\title{
Programs to improve adolescent sexual and reproductive health in the US: a review of the evidence
}

This article was published in the following Dove Press journal:

Adolescent Health, Medicine and Therapeutics

7 April 2015

Number of times this article has been viewed

\author{
Jennifer Manlove \\ Heather Fish \\ Kristin Anderson Moore \\ Child Trends, Bethesda, MD, USA
}

Correspondence: Jennifer Manlove Child Trends, 7315 Wisconsin Avenue, Suite I200W, Bethesda, MD 208I4, USA Email jmanlove@childtrends.org
Background: US adolescents have high rates of teen pregnancy, childbearing, and sexually transmitted infections (STIs), highlighting the need to identify and implement effective programs that will help improve teen sexual and reproductive health.

Materials and methods: This review identified 103 random-assignment evaluations of 85 programs that incorporated intent-to-treat analyses and assessed impacts on pregnancy, childbearing, STIs, and their key determinants - sexual activity, number of sexual partners, condom use, and other contraceptive use - among teens. This review describes the evidence base for five broad program approaches, including abstinence education, comprehensive sex education, clinic-based programs, youth development programs, and parent-youth relationship programs. We also describe programs with impacts on key outcomes, including pregnancy/childbearing, STIs, and those that found impacts on both sexual activity and contraceptive use.

Results: Our review identified 52 effective programs: 38 with consistent impacts on reproductive health outcomes, and 14 with mixed findings (across subpopulations, follow-ups, or multiple measures of a single outcome). We found that a variety of program approaches produced impacts on sexual and reproductive health outcomes. Parent-youth relationship programs and clinicbased program evaluations more frequently showed impacts than other program approaches, although we also identified a number of abstinence-education, comprehensive sex education, and youth-development programs with impacts on sexual and reproductive health outcomes. Overall, we identified nine program evaluations with impacts on teen pregnancies or births, five with impacts on reducing STIs, and 15 with impacts on both delaying/reducing sexual activity and increasing contraceptive use (including condom use).

Conclusion: Future efforts should conduct replications of existing program evaluations, identify implementation components linked to impacts, rigorously evaluate programs that appear promising, and expand the evidence base on programs that impact hormonal and long-acting contraceptive method use.

Keywords: reproductive health, evidence-based programs, teen pregnancy, adolescence

\section{Introduction}

US teen-birth rates have declined across several decades, and the 2013 birth rate of 26.5 births per 1,000 teens ages 15-19 years was the lowest recorded birth rate. ${ }^{1}$ However, US teen-birth rates remain higher than those in other developed countries, and are 1.5 times the rate in the UK, more than two times the rate in Canada, and more than five times the rate in Sweden. ${ }^{2}$ Currently, an estimated one in nine teens in the US will have a birth before they reach age 20 years (Child Trends, unpublished data, 2014). Notably, the majority of teen births (77\%) are unintended, including 58\% that occurred sooner than the teen planned and $19 \%$ that were unwanted. ${ }^{3}$ Teen-birth rates are especially high among 
racial and ethnic (Child Trends, unpublished data, 2014); black and Hispanic teens have birth rates that are double the rate of whites in the US, although many of these differences reflect the socioeconomic disadvantage of these populations. ${ }^{4}$

Teen childbearing is linked to a host of negative outcomes among teen parents, their children, and society as a whole. Despite the fact that many teen parents were disadvantaged before they became parents, researchers have found associations between early parenthood and lower educational attainment and higher poverty rates among mothers ${ }^{5}$ and poorer academic and behavioral well-being among their children. ${ }^{6}$ Moreover, some research has found links between delaying childbearing in one generation (with an accompanying increase in educational attainment) and greater economic well-being of the next generation. ${ }^{7}$ Also, a substantial proportion of teen births (17\% in 2013) are higher-order births, ${ }^{8}$ which are linked to even greater disadvantage among teen parents and their children. ${ }^{9}$ Moreover, teen childbearing costs US taxpayers billions of dollars through public assistance payments and through social services, such as health care and child welfare. ${ }^{10}$

US adolescents also have high rates of sexually transmitted infections (STIs). Almost half of the 20 million STIs that are reported in the US each year occur in adolescents and young adults. ${ }^{11}$ One study of sexually active teen females (ages 14-19 years) found that almost four in ten had at least one of five common STIs. ${ }^{12}$ STIs are an ongoing threat to adolescent health and well-being, and if left untreated they can lead to infertility, pregnancy complications, organ damage, and even death. ${ }^{13}$ These factors highlight the need to identify a variety of effective evidence-based programs that have found impacts on improving adolescent reproductive health through rigorous evaluations.

Key determinants of teen pregnancy and/or STIs include the timing and frequency of sexual activity, the number of sexual partners, and the consistent use of condoms and other effective methods of contraception. Almost half of high school teens have ever had sexual intercourse, including nearly two-thirds of 12 th graders. ${ }^{14}$ Teens who are younger at first sex are less likely to use contraception, and are at a greater subsequent risk of a teen birth or STI. ${ }^{6}$ Although many US teens report using contraception at last sex ( $86 \%$ of 15 - to 19 -year-old females and $93 \%$ of 15 - to 19 -year-old males in 2006-2010), less than half of female teens use hormonal methods, and even fewer use the most effective, long-acting methods, such as intrauterine devices or implants. ${ }^{6}$ The lower use of these highly effective methods contributes to the higher teen-birth rates in the US compared with other industrialized countries. ${ }^{15}$ In addition, many teens use condoms inconsistently. ${ }^{16}$ Therefore, programs that help teens delay the timing of first sex or increase condom use or other contraceptive use can help reduce high rates of teen pregnancy and STIs. A recent study found that implementing evidence-based teenpregnancy prevention programs is a cost-effective strategy to save taxpayer dollars. ${ }^{17}$

Polling data suggest that there is continued broad public support for sexual and reproductive health education for adolescents, ${ }^{18}$ and the US government has several funding initiatives to implement and scale up evidence-based approaches to teen-pregnancy prevention. ${ }^{19}$ However, the current list of evidence-based teen-pregnancy programs that are approved for replication is still fairly limited, ${ }^{20}$ and providers describe the need for on-the-ground adaptations of existing programs to make them more relevant for diverse teen populations. ${ }^{21,22}$ As the US population, particularly the youth population, continues to become increasingly diverse, it is vital that communities have a variety of program approaches tailored to the needs of their target populations. This highlights the need to identify a variety of rigorously evaluated program approaches and settings with impacts on adolescent reproductive health outcomes.

\section{Materials and methods \\ Review criteria}

This study examined evaluations of reproductive health programs that incorporated random-assignment and intentto-treat analyses (including data for all subjects who were randomly assigned in the analysis, regardless of their participation in the study). Evaluations were identified through peer-review articles and published (or unpublished) evaluation reports. We did not set a requirement for publishing date, so articles were identified from 1990 to 2014. All of these evaluations are included in Child Trends' What Works/LINKS (Lifecourse Interventions to Nurture Kids Successfully) database, ${ }^{23}$ a database of over 700 social intervention programs to assess child or youth outcomes related to education, life skills, and social/emotional, mental, physical, behavioral, or reproductive health. LINKS includes evaluations of programs that do and that do not have positive impacts, allowing us to assess approaches that appear to be more and less effective, based on the rigorous evaluations available to date. We limited the review to evaluations of programs that were implemented primarily with adolescents under the age of 18 years, that did not target expectant and parenting adolescents, and assessed impacts on reproductive health outcomes and their key behavioral determinants. These included: sexual behaviors 
(sexual initiation or the percentage of teens who had ever had sex, frequency or recency of sex, number of sexual partners, anal/oral sex, sex under the influence of drugs or alcohol); condom use or contraceptive use (any contraceptive/condom use, consistency of use, hormonal method use, use of longacting reversible methods, such as intrauterine devices and implants); STIs (including self-reports and -testing); and pregnancies or births (based on self-reports).

This review identified 103 evaluations of 85 reproductive health program models that were used for this study. There are more evaluations than programs, because 15 program models were evaluated two or more times and differed from the original implementation based on population, setting, or program components. These programs were implemented in a variety of settings (with several that were implemented in two or more settings), including 54 that were implemented in schools, 26 in clinics, 20 in community-based organizations, and 18 in other settings, such as the home and juvenile justice facilities.

To help organize our findings, we divided our review into five broad categories of sexual and reproductive health programs: 1) abstinence-only or abstinence-based education programs (14 evaluations), 2) comprehensive sex-education programs (47 evaluations), 3) clinic-based programs (14 evaluations), 4) youth-development programs (17 evaluations), and 5) parent-youth relationship programs (eleven evaluations). We also describe evaluations - across program categories - that found impacts on key outcomes, including pregnancy or childbearing, STIs, and those that found impacts on both sex and contraception.

This review does not focus on the magnitude of the impacts found, but rather the number of statistically significant impacts found. For example, some program evaluations assessed impacts on multiple measures of a single outcome (such as condom use at last sex, condom use in the past 3 months, and consistent condom use), on more than one subpopulation (such as males and females; whenever provided, we examined impacts based on analyses of the full sample; we only took into account subpopulation analyses [such as by sex] if an evaluation did not report analyses for the full sample) or on multiple follow-ups (such as at posttest and first and second follow-ups). In these cases, our review assessed the level of evidence across these measures, populations, or follow-ups. The impacts of the program outcomes reviewed for this brief are reported in the following three categories: Found to work, Mixed findings, and Not found to work, all of which are described in the following sections. All of the tables in this report are organized by these categories. At least two researchers reviewed each evaluation to confirm the coding of program impacts.

\section{Found to work}

Programs in this category found positive and statistically significant impacts on the majority of measures assessed within an outcome or the majority of subpopulations (when full sample results were unreported) or follow-ups. For example, a program that found an impact on condom use at last sex and consistent condom use but did not find an impact on condom use in the last 3 months would be categorized as "found to work" for condom use, because it found impacts on the majority of measures of condom use. Programs were also considered to have worked for an outcome if the impact was delayed, such as a program that found no impact on pregnancy at posttest, but found a positive impact at follow-up.

\section{Mixed findings}

Programs in this category found varied impacts on particular outcomes, either at different follow-ups, for different subgroups, or on different measures. For example, a program that found significant reductions in the initiation of sex at posttest but had no impact at follow-up would receive a "mixed" coding.

\section{Not found to work}

Programs in this category had nonsignificant, marginally significant, or negative impacts on the majority of measures assessed. Note that some programs in this category have shown some impacts, but not for the majority of subgroups, follow-ups, or measures of the same outcome. For example, a program that found an impact on sexual initiation at posttest but not at two other follow-ups would receive a "not found to work" coding for sexual initiation because there were impacts for only one of three time points, and impacts diminished over time.

\section{Effective programs}

We describe programs as "effective" if they worked or had mixed findings for at least one outcome. The tables are separated by effectiveness. All programs that were not found to work for any outcome are included in Table S1, while those that worked or had mixed findings (effective programs) are included in Tables 1-5.

\section{Results}

Overall, we identified 52 program evaluations out of 103 reviewed that were effective for sexual and reproductive 


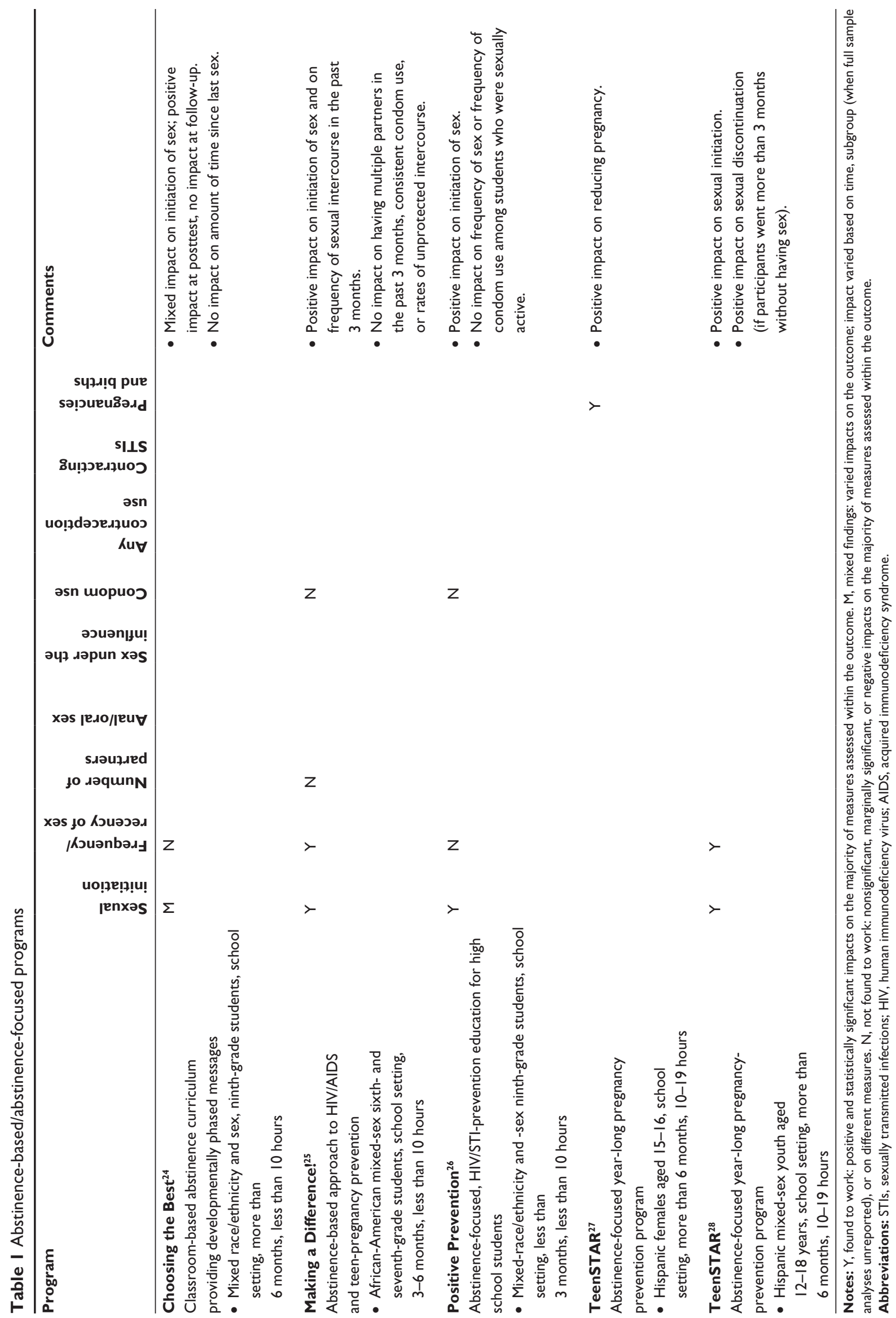


health outcomes, including 38 that worked for at least one outcome and 14 with mixed impacts across follow-ups, subpopulations, or separate measures of a single outcome. These 52 programs had impacts across a range of program approaches and for a variety of teen populations, program durations, and settings (as highlighted in Tables 1-5).

Overall, 31 program evaluations were effective for some measure of sexual activity, including 14 program evaluations that delayed sexual initiation, 15 that reduced frequency of sexual activity, nine that reduced sexual partners, three that delayed or reduced oral or anal sex, and two that reduced sex under the influence. We also identified 31 program evaluations that were effective for condom use or contraceptive use, including 25 that increased condom use and nine that increased contraceptive use more generally. Five programs were effective for reducing STIs, and nine reduced pregnancies or births.

In the following sections, we discuss the findings for the five program approaches, including abstinence-based education, comprehensive sex education, clinic-based approaches, youth-development approaches, and parent-youth education programs. We also discuss findings for programs that found impacts on pregnancy or births and STIs, and those that found impacts on both sexual activity and contraceptive use. Our review describes the number and percentage of evaluated programs that were effective for each category/outcome, as well as program and implementation characteristics of effective programs.

\section{Abstinence-based education programs}

Abstinence-based programs, which promote abstinence above all other approaches, were sometimes found to be effective. Of the 14 identified evaluations of abstinenceeducation programs, only about a third of (five total) were effective by our definition. These programs are described in Table 1; abstinence-education programs that did not work are described in Table S1. All of the effective abstinence-based program evaluations were school-based programs with multiple 45-minute to 1-hour sessions spread out over several months or multiple years. ${ }^{24-28}$ These programs emphasized goals and dreams while promoting abstinence beliefs and attitudes. Although all five of the effective programs mentioned contraceptive use, only one incorporated condom-use skill building. ${ }^{26}$

Four of the effective abstinence-based programs worked for at least one outcome and one had mixed findings. As shown in Table 1, four programs delayed sexual initiation (including three that found consistent impacts ${ }^{25,26,28}$ and one that found a mixed impact, on some but not all follow-ups $)^{24}$ and two reduced sexual frequency. ${ }^{25,28}$ One program reduced pregnancies or births. ${ }^{27}$ However, none of the abstinence programs reduced the number of sexual partners, increased condom or contraceptive use, or reduced STIs. None of these program evaluations measured anal sex, oral sex, or sex under the influence of alcohol or drugs.

\section{Comprehensive sex-education programs}

Comprehensive sex-education programs focus on improving reproductive health outcomes (eg, preventing pregnancy, increasing STI/human immunodeficiency virus [HIV] knowledge) and in general promote both abstinence and contraceptive/condom use. Overall, less than half of the evaluations of comprehensive programs were effective (21 of 47 worked or had mixed findings for at least one outcome; Table 2; comprehensive sex-education programs that did not work are in Table S1), and they varied by length and setting. Eight of the effective programs were full school-year or multiyear programs that were implemented in $\mathrm{school}^{29-37}$ and community-based settings. ${ }^{38}$ Several of these longer-duration programs included homework assignments, ${ }^{31-33,35,36}$ a parent/ family component (such as parent-youth dialog or a parent session), ${ }^{31-33,35-38}$ or peer-to-peer interaction/mentoring. ${ }^{34-36,38}$ The remaining 13 effective comprehensive sex-education programs lasted less than 3 months or included less than 10 hours of programming focused on education and skill training. ${ }^{25,39-47}$ Their program settings varied, with several that were implemented in schools ${ }^{25,46,48-50}$ and communitybased organizations, ${ }^{40-42,44,48,51}$ some that were implemented in clinic settings, ${ }^{39,44-46}$ one that was implemented partially in the home, ${ }^{42}$ and two in juvenile detention or drug centers. ${ }^{43,47}$ Most (seven) of these shorter-duration programs targeted reducing the risk of STIs/HIV, ${ }^{39,44,45}$ including three evaluations of Be Proud! Be Responsible! ${ }^{49-51}$ and one evaluation of ¡Cuídate! ${ }^{48}$ (an adaptation of Be Proud! Be Responsible! for Hispanics).

Of the 21 effective comprehensive sex-education evaluations (including both shorter- and longer-duration programs), 13 worked for at least one outcome, and eight had mixed findings based on varied impacts across measures, subpopulations, treatment groups, or follow-ups. As shown in Table 2, almost all of the effective comprehensive sex-education program evaluations measured impacts on both sexual activity and contraceptive use. Sixteen of these evaluations were effective for at least some measure of sexual activity, including six that were effective for delaying sexual initiation (including two with consistent impacts ${ }^{37,38}$ and four with mixed 


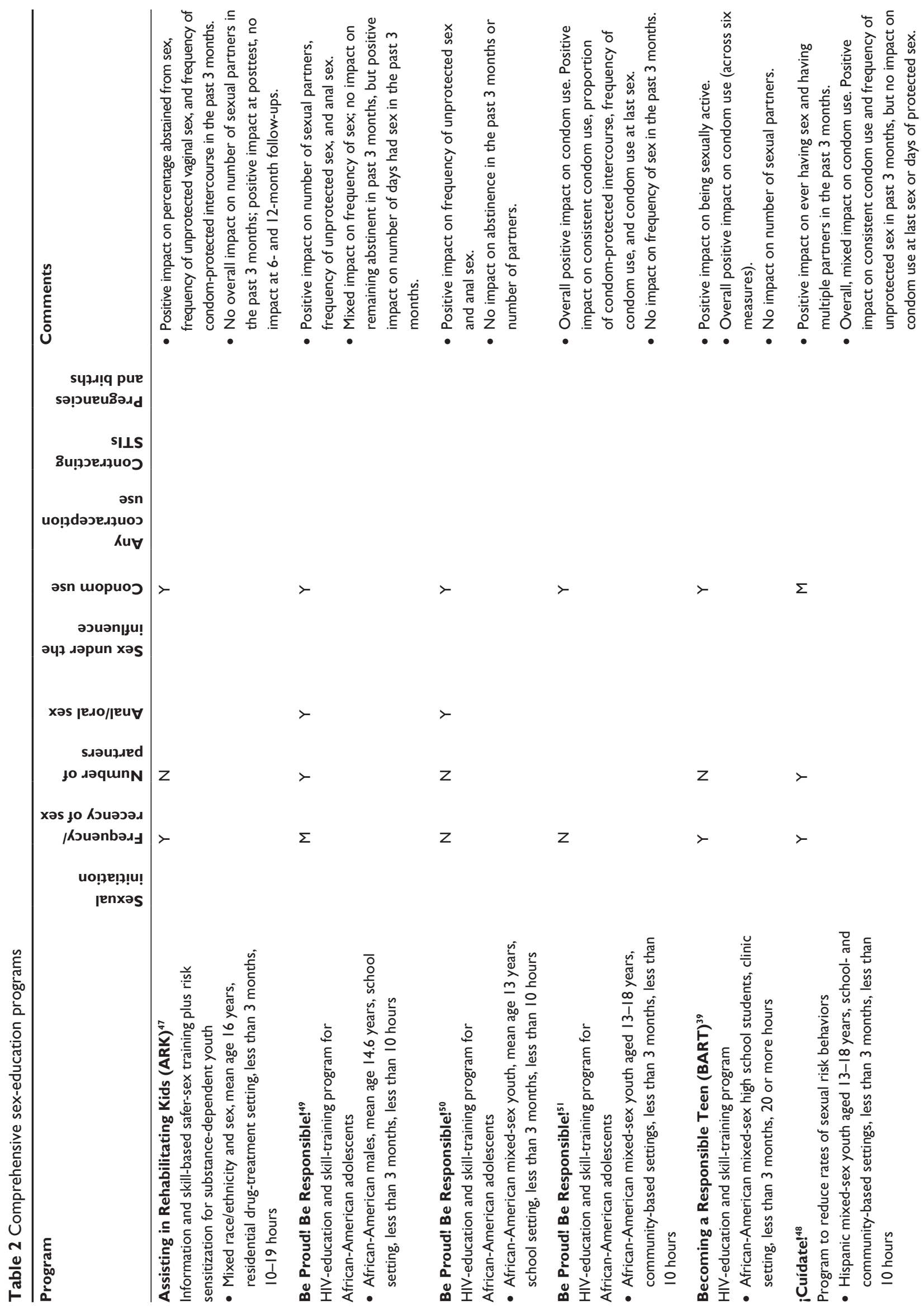




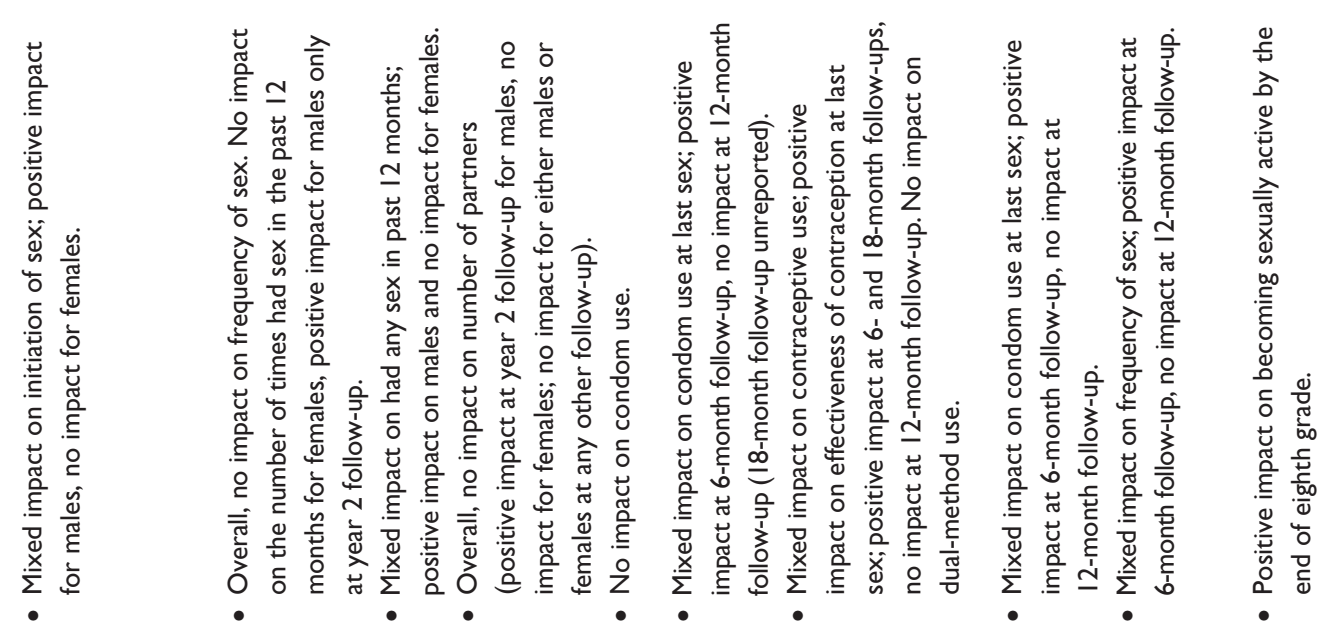

$\Sigma$

z

$\Sigma$

$\Sigma$

z

Z

$\Sigma$

$\Sigma$
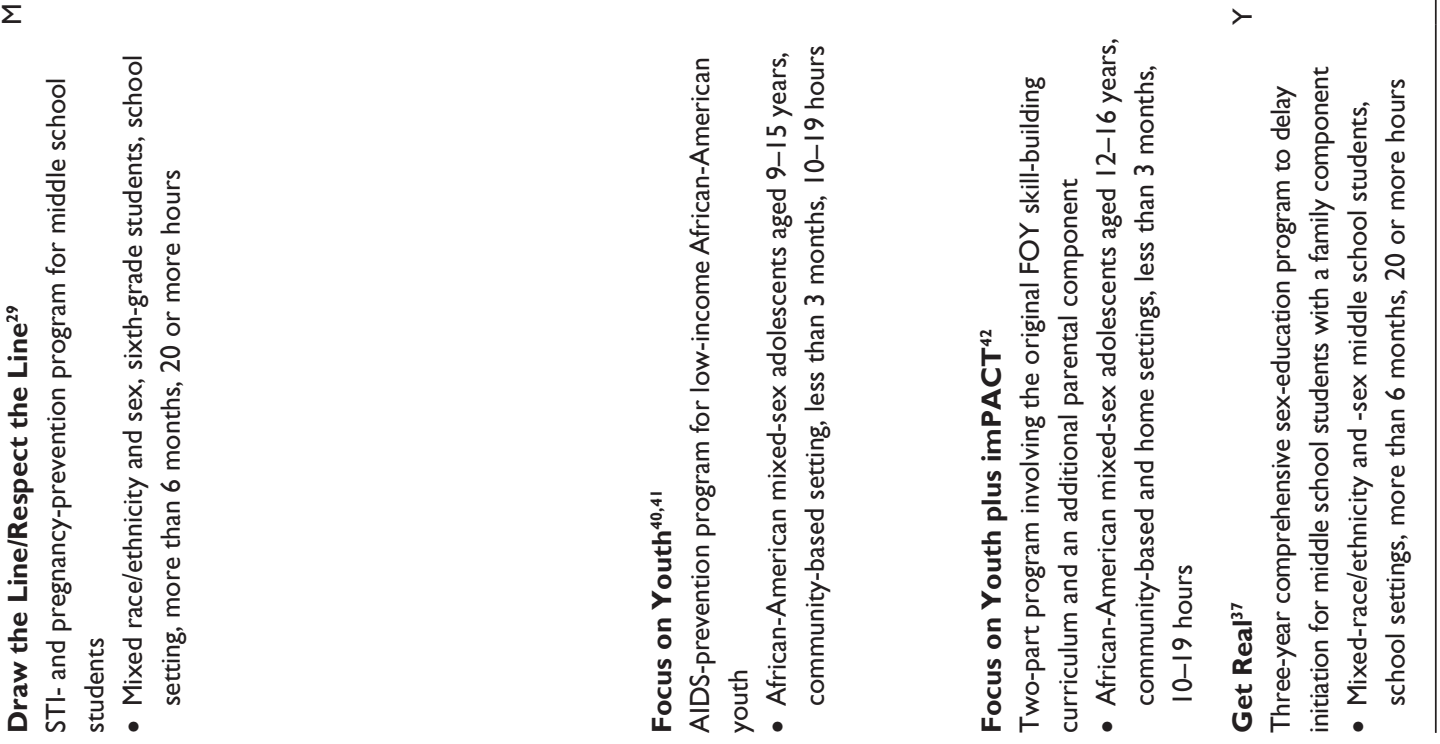


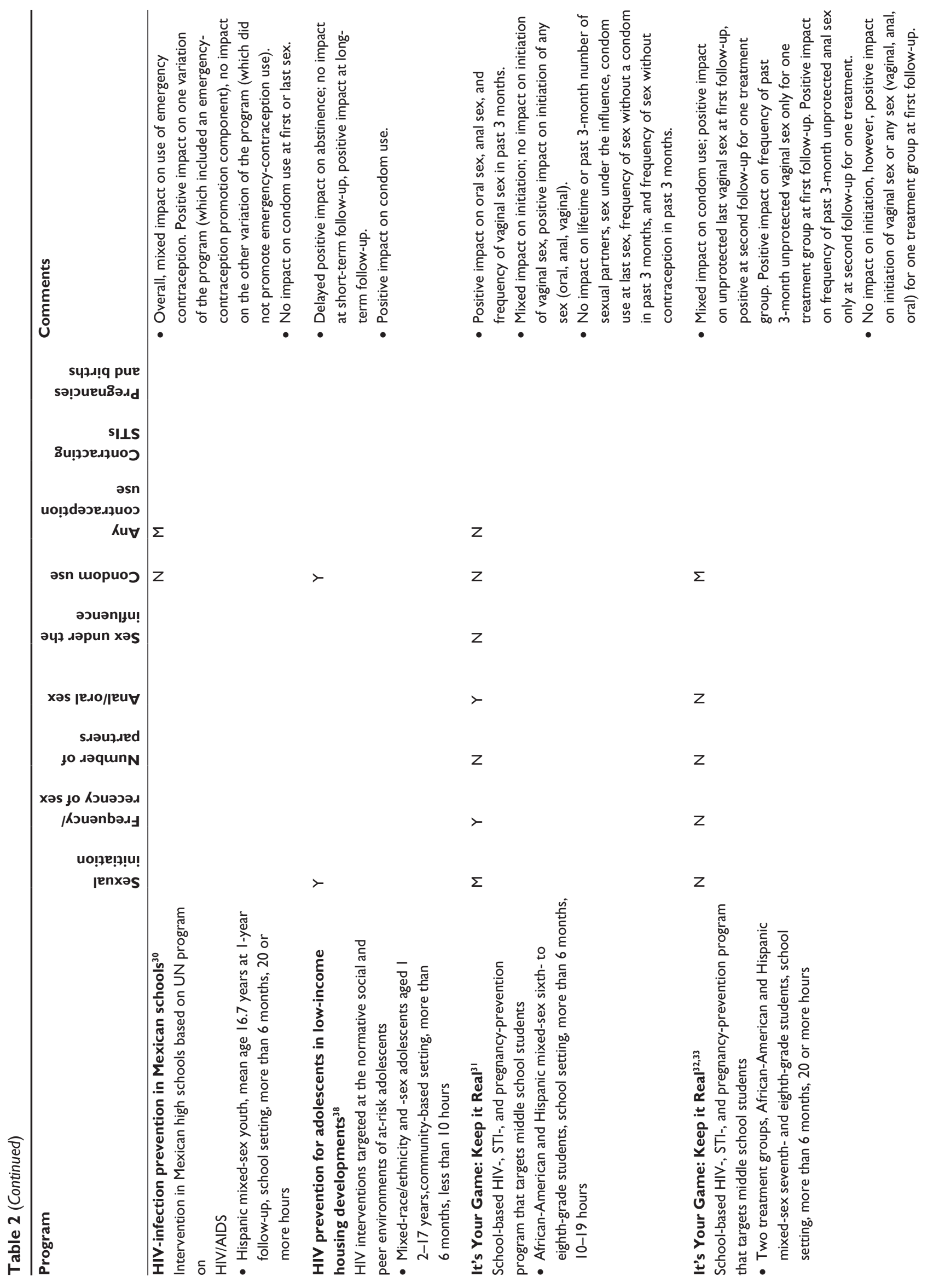



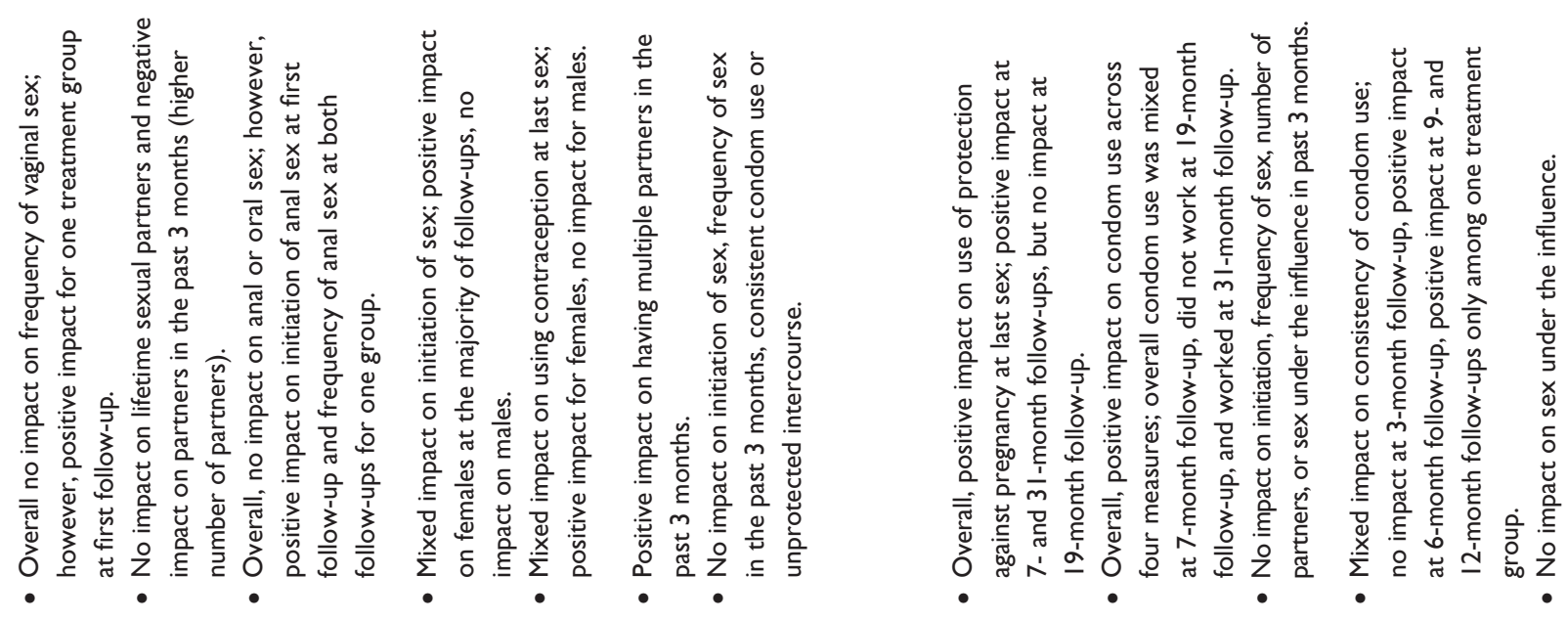

$\Sigma$

z

$\Sigma$

z

z

$\Sigma$

z

z
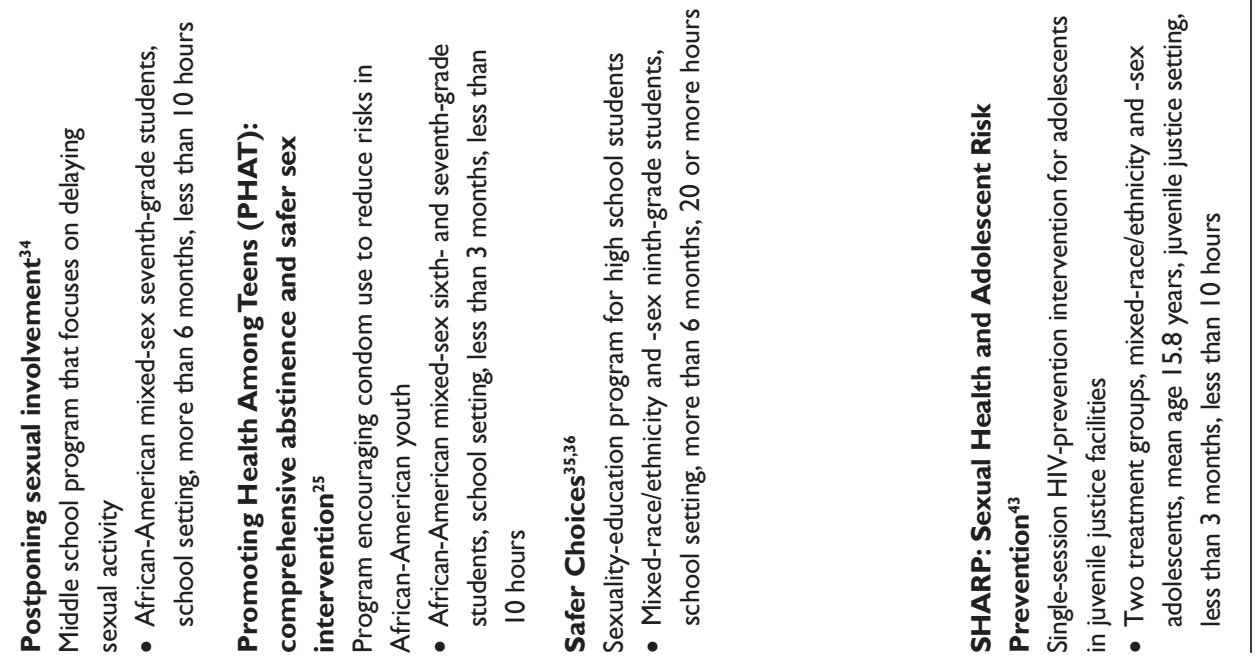


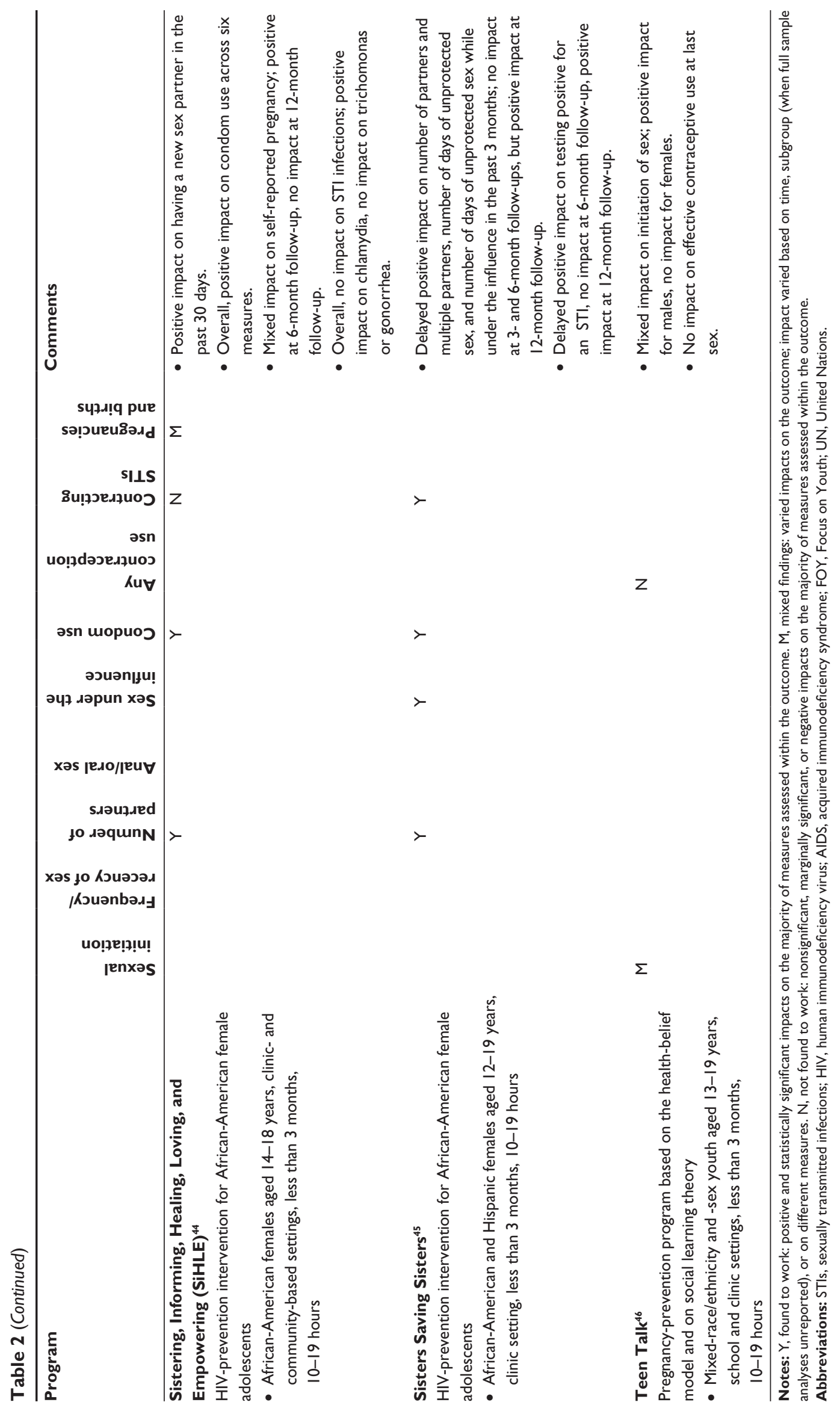


impacts), ${ }^{29,31,34,46}$ six for reducing sexual frequency (including four with consistent impacts ${ }^{31,39,47,48}$ and two with mixed impacts), ${ }^{42,49}$ five for reducing the number of sexual partners, ${ }^{25,44,45,48,49}$ three that were effective for decreasing anal or oral sex, ${ }^{31,49,50}$ and one for reducing sex under the influence. ${ }^{45}$ Another 14 comprehensive sex-education programs found impacts on condom use (including nine with consistent impacts $^{35,36,38,39,44,45,47,49-51}$ and five with mixed impacts). ${ }^{32,33,40-43,48}$ Four programs were effective for increasing contraceptive use (including one with consistent impacts ${ }^{35,36}$ and three with mixed findings). ${ }^{30,34,40,41}$ In addition, one program was effective at reducing laboratory-tested STIs, ${ }^{45}$ and one found a mixed impact on pregnancies or births. ${ }^{44}$

\section{Clinic-based programs}

Clinic-based programs were designed for implementation in a clinic or were implemented by clinic staff or physicians. While several other types of programs, including comprehensive sex-education programs, incorporated a clinic component, clinic-based programs were generally designed exclusively for use in a clinic setting and targeted adolescents seeking clinical services. Overall, these programs were frequently found to be effective; nine clinic-based program evaluations (of 14 total) were effective for at least one outcome or population (Table 3; clinic-based programs that did not work are listed in Table S1). All of the effective clinic-based programs were implemented with youths aged 14-18 years, and most lasted less than 3 months or had less than 10 contact hours with participants (although one program incorporated an 18-month intervention that combined case management, peer leadership, and service learning). ${ }^{52,53}$ Notably, seven of these programs were implemented with a female-only population, ${ }^{52-59}$ one was implemented only with males, ${ }^{60}$ and one was with mixed sexes. ${ }^{61}$ Clinic-based programs frequently incorporated one-on-one sessions, ${ }^{52-54,56,57,60,61}$ sometimes in conjunction with interactive group sessions. ${ }^{52,53,56} \mathrm{~A}$ few clinic-based programs used only group sessions. ${ }^{55,58}$ One effective clinic-based program implemented a four-session video-only intervention, ${ }^{59}$ and two others incorporated videos in supplement to individual counseling. ${ }^{57,60}$

Of the nine effective clinic-based program evaluations, six found consistent impacts for at least one outcome, and three had mixed findings. As shown in Table 3, four clinicbased program evaluations were effective for some measure of sexual activity; three were effective at reducing sexual frequency (including two that found consistent impacts ${ }^{52,53,58}$ and one that found a mixed impact across follow-ups), ${ }^{59}$ and one that found a mixed impact on reducing the number of partners (across follow-ups). ${ }^{61}$ None of these program evaluations found consistent impacts for sexual initiation, and none measured anal or oral sex or sex under the influence. Six program evaluations were effective at increasing condom use (including three with consistent findings ${ }^{52,53,55,58}$ and three that reported mixed findings, based on various measures of condom use in one study, ${ }^{54}$ and varying across follow-ups for two others). ${ }^{57,61}$ Two program evaluations were effective at increasing contraceptive use. ${ }^{52,53,60}$ In addition, three program evaluations were effective at reducing STIs (including two with consistent impacts ${ }^{56,61}$ and one with a mixed impact with a positive impact on self-reported STIs, but no impact on clinically tested infection), ${ }^{59}$ and one that was effective at reducing pregnancies or births. ${ }^{58}$

\section{Youth-development programs}

Youth-development programs focused on school achievement or health outcomes (many in combination with reproductive health outcomes) or were designed to increase prosocial behaviors, such as cooperation. Overall, about half of the evaluated youth-development programs were effective: eight (of 17 total) worked or found mixed impacts for at least one outcome (Table 4; Table S1 lists youth-development programs that were not found to work). All of these effective programs were longer in length, reporting a duration of more than 6 months or more than 20 contact hours with participants. Three programs - including two implementations of the Children's Aid Society (CAS)-Carrera Program - were intensive, multiyear, and multicomponent interventions. ${ }^{62-64}$ Four programs, including two evaluations of the Teen Outreach Program, included servicelearning components that combined community volunteering with classroom-based discussions. ${ }^{64-67}$ One program included individualized clinical services addressing life-planning, goalsetting, and coping skills, in addition to medical and reproductive health clinical services. ${ }^{68}$ Also, one program worked with fifth graders to promote social and character development and positive action. ${ }^{69}$ Most of the youth-development programs with impacts included some type of sex education in combination with other activities.

Of the eight effective youth-development program evaluations, seven worked for at least one outcome, and one had mixed findings. As shown in Table 4, four youth-development program evaluations were effective at reducing some measure of sexual activity, including three that were effective at delaying sexual initiation ${ }^{63,67,69}$ and three that were effective at reducing sexual frequency (including two with consistent impacts $^{67,68}$ and one that found a mixed impact by sex). ${ }^{63}$ 


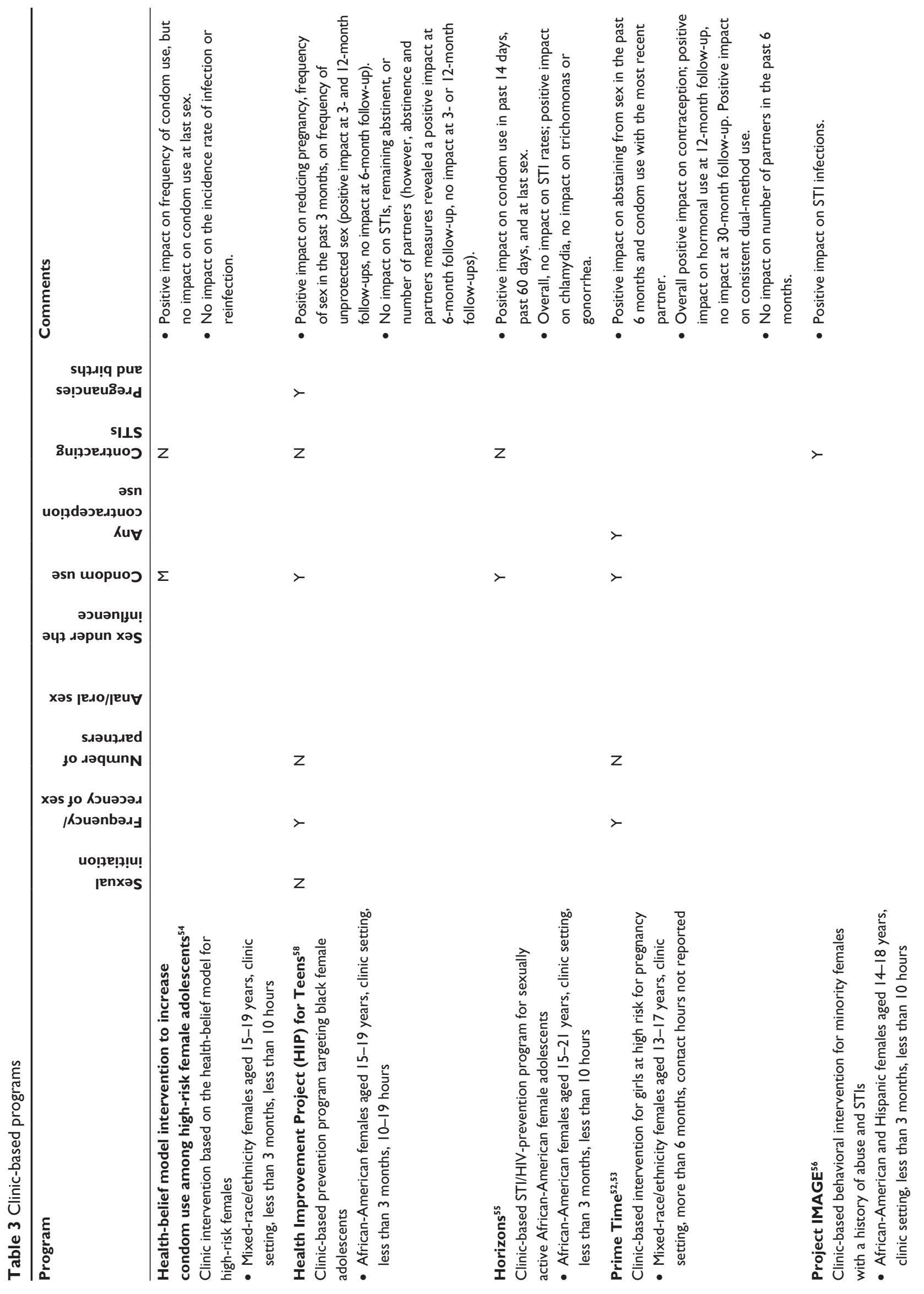



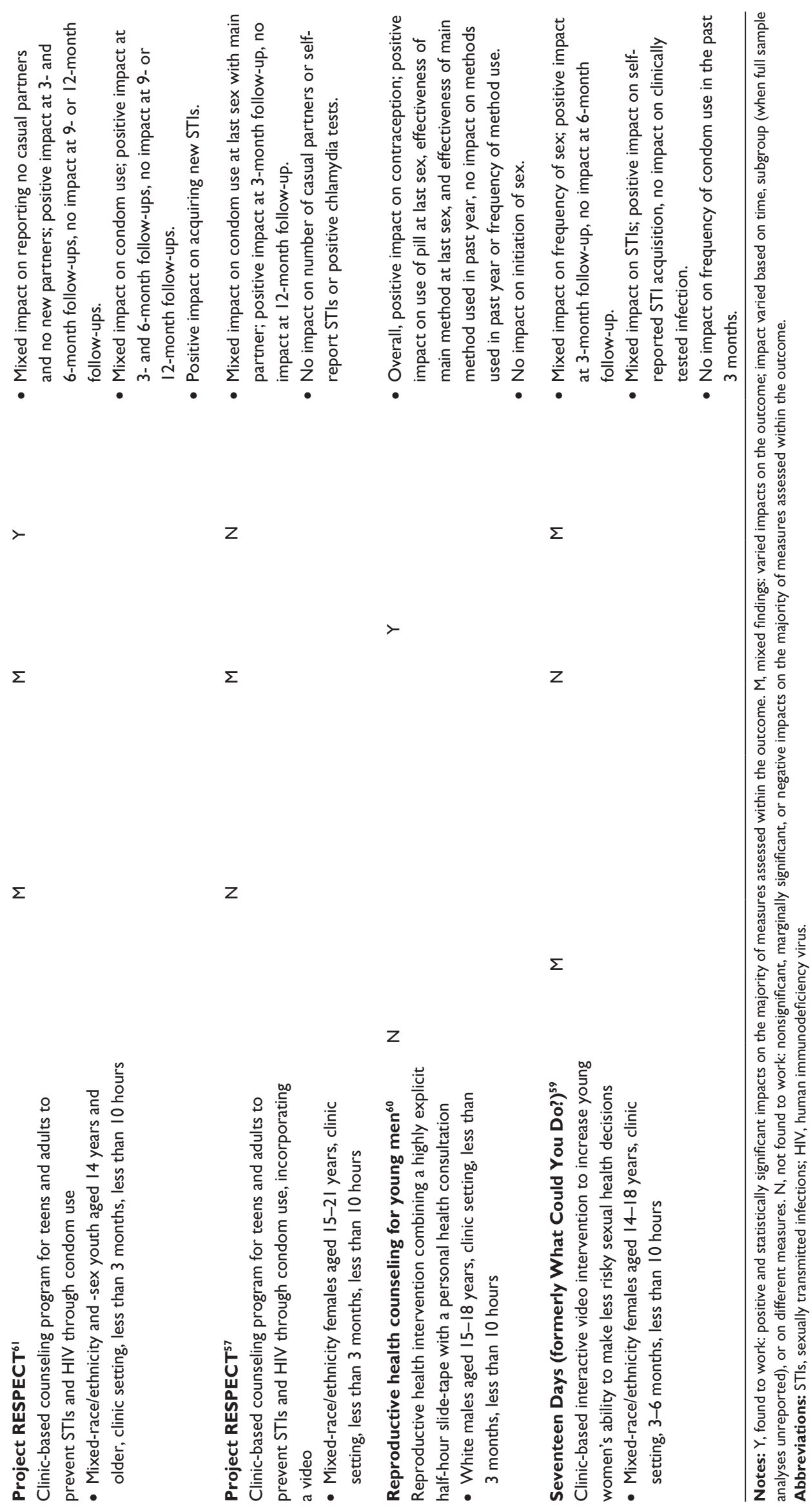


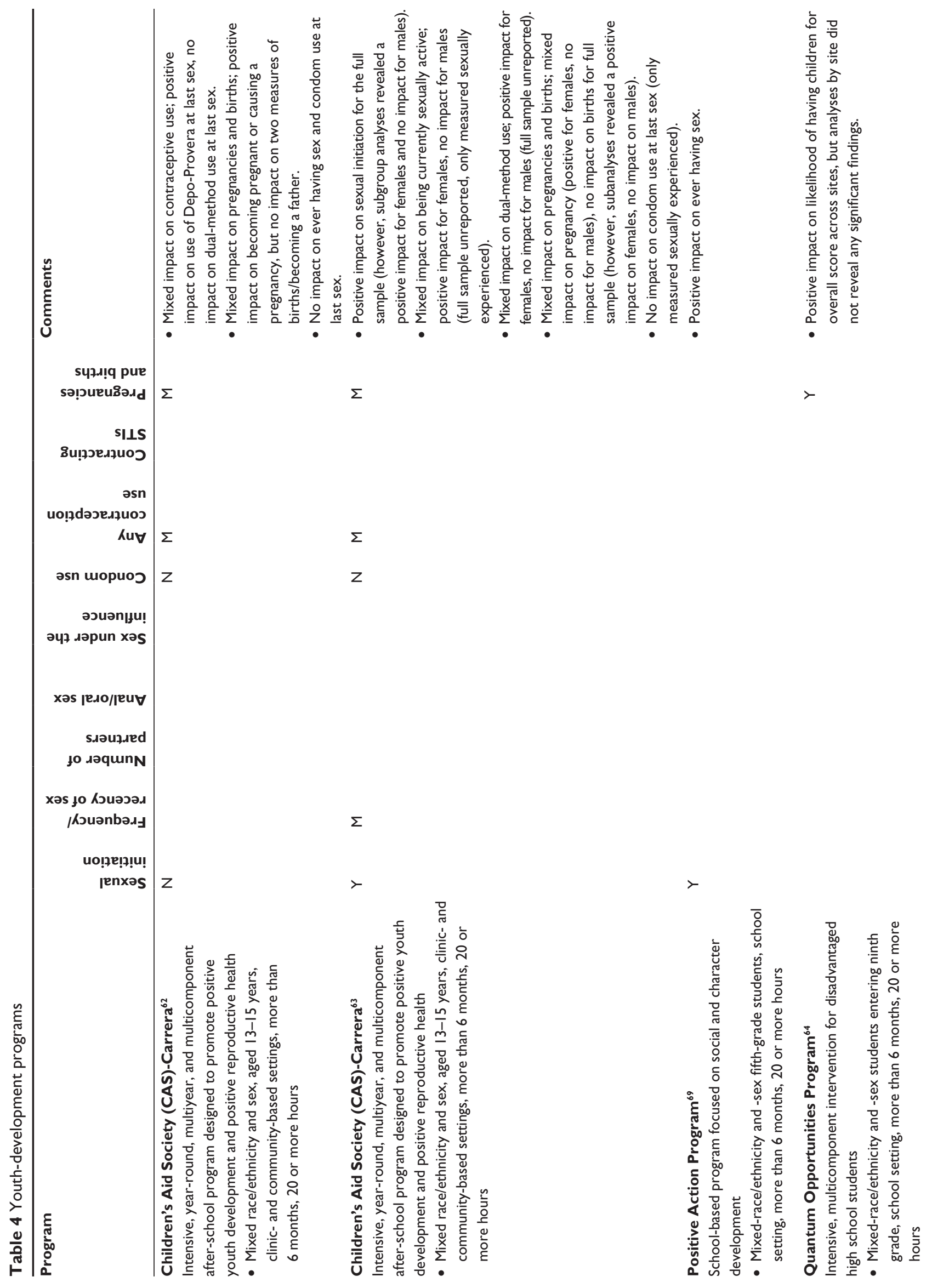




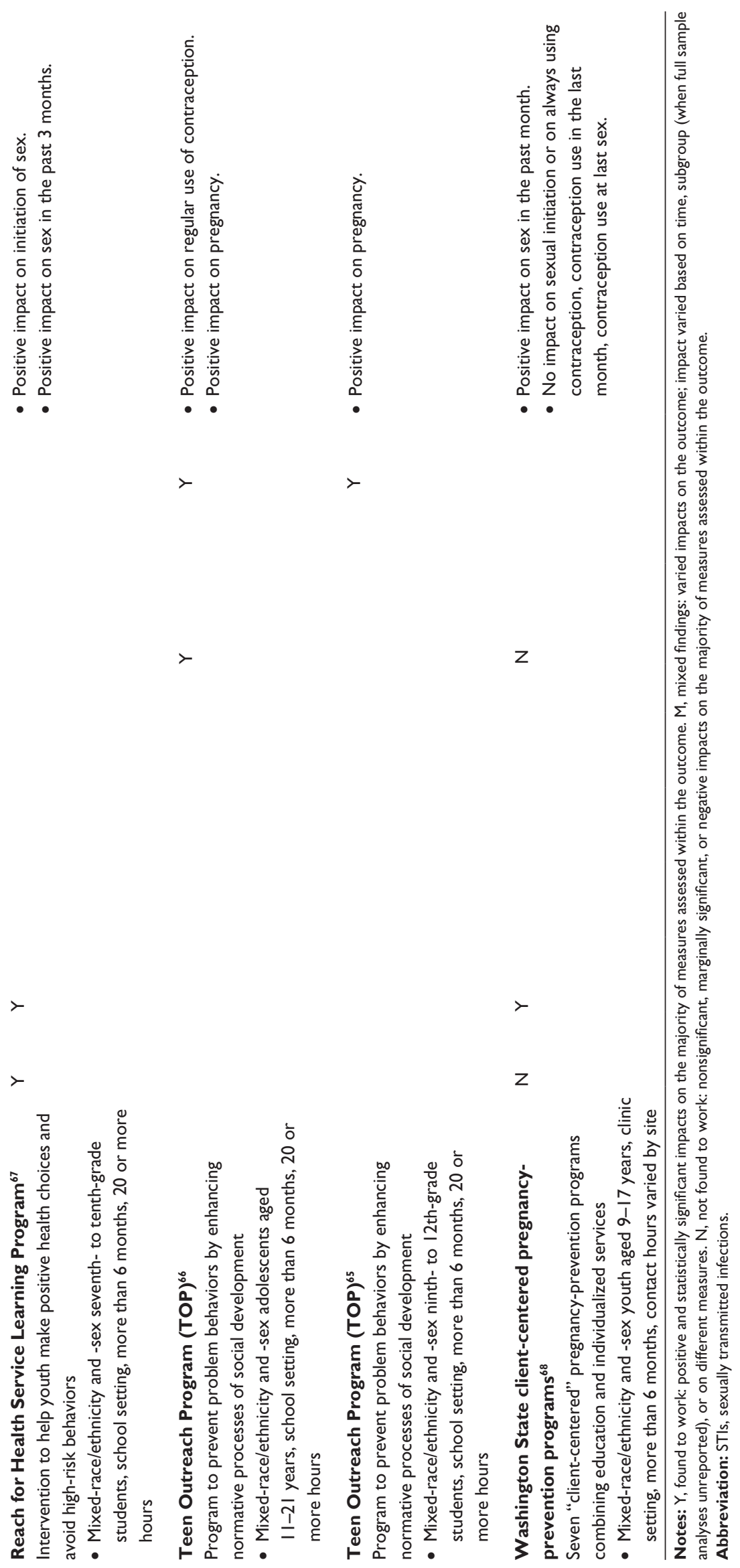


None of these program evaluations measured impacts on the number of partners, oral or anal sex, or sex under the influence. No youth-development program evaluations were effective at increasing condom use, but three were effective at increasing contraceptive use (including one with consistent impacts ${ }^{66}$ and two with a mixed impact, one by sex, ${ }^{63}$ and another with an impact on injectable contraceptive methods but not on dual-method use). ${ }^{62}$ In addition, no youth-development program evaluations measured STIs, but three found consistent impacts on pregnancies or births, ${ }^{64-66}$ and two had mixed findings. ${ }^{62,63}$

\section{Parent-youth relationship programs}

This category of programs aimed to improve parent-youth relationships, with a particular focus on communication about sexual behavior and romantic relationships. Overall, these programs were frequently effective. Nine parentyouth relationship-program evaluations (of eleven total) worked or had mixed findings for at least one outcome or population, and they are described in Table 5 (programs that did not work are included in Table S1). These parentyouth relationship programs varied in their implementation approaches. For example, three evaluations found behavioral impacts of the program Familias Unidas, a home-based sex-education intervention focused on increasing parental involvement in Hispanic families, including two that were implemented on their own with different age-groups ${ }^{70,71}$ and one that was implemented in combination with PATH (Parent-Preadolescent Training for HIV Prevention), ${ }^{72}$ an HIV-prevention curriculum to train parents to become effective HIV educators for their children. Another three parent-youth relationship programs that found impacts were implemented in clinic settings, including one that focused on parents with acquired immunodeficiency syndrome, ${ }^{73}$ one with group sessions for mothers and additional youth modules and parent-child homework assignments, ${ }^{74}$ and a third that was implemented with a sample of divorced mothers and their children. ${ }^{75}$ Another two programs were implemented in community settings, including a father-son HIV-prevention program focused on African-American families ${ }^{76}$ and an HIVprevention program for African-American mothers and their children. ${ }^{77}$ The final parent-youth relationship program was for homeless and runaway teens and their parents, and was implemented in the setting of their choosing. ${ }^{78}$ Parent-youth relationship programs were generally implemented with younger youth: six of the nine programs were implemented primarily with youth aged 13 years or younger, ${ }^{70,72,74-77}$ and three were implemented with a broader age range. ${ }^{71,73,78}$
Of the nine effective parent-youth relationship-program evaluations, eight found consistent impacts for at least one outcome, and one had mixed findings. As shown in Table 5, four of these program evaluations were effective for reducing some measure of sexual activity, including one that found consistent impacts on delaying sexual initiation, ${ }^{74}$ one that was effective at reducing sexual frequency, ${ }^{74}$ three that were effective at reducing the number of partners (including two that found consistent impacts ${ }^{71,78}$ and one that found a mixed impact across program implementations), ${ }^{75}$ and one that found impacts on sex under the influence ${ }^{71}$ (no parentyouth programs were effective for reducing anal or oral sex). Another five parent-youth relationship-program evaluations were effective at increasing condom use, ${ }^{70-72,76,77}$ but no evaluations measured impacts on contraceptive use. In addition, one effective parent-youth relationship-program evaluation found consistent impacts for self-reported STIs, ${ }^{72}$ and another reduced pregnancies or births. ${ }^{73}$

\section{Programs with impacts on key outcomes}

This section highlights programs that were effective at improving key sexual and reproductive health outcomes, including those that were effective at reducing teen pregnancies, births, or STIs. We also describe programs that found impacts on both sexual and contraceptive or condom-use behaviors.

\section{Programs that were effective at reducing teen pregnancies, births, or STIs}

Our review highlights several program evaluations with impacts on teen pregnancies, births, or STIs. Of the 33 program evaluations that measured pregnancies or births, nine found an impact (including six that found consistent impacts $^{28,58,64-66,73}$ and three with mixed findings across follow-ups). ${ }^{44,62,63}$ These nine program evaluations represent all program approaches: one was abstinence education, ${ }^{28}$ one was comprehensive sex education, ${ }^{44}$ one was clinic-based approaches, ${ }^{58}$ five were youth development, ${ }^{62-66}$ and one was a parent-youth relationship program. Three of these programs were implemented only with females, ${ }^{28,44,58}$ and six with mixed sexes. ${ }^{62-66,73}$ Most were implemented in schools (four) ${ }^{28,64-66}$ or clinics (two), ${ }^{58,73}$ and three were implemented in both a clinic and a community-based organization. ${ }^{44,62,63}$ While it appears that youth-development approaches are especially likely to be effective at reducing teen pregnancies, given the diversity of effective approaches, it is possible that the effective programs share one or more subtle similarities not visible in evaluation reports. 
Of the 23 program evaluations that measured STIs, five were effective, including four that found consistent impacts $^{45,56,61,72}$ and one that had mixed findings. ${ }^{59}$ Most of the programs with impacts on STIs were based on testing (three), ${ }^{45,56,61}$ although one was based on self-report, ${ }^{72}$ and one used both. ${ }^{59}$ Of these five effective programs, three were clinic-based interventions, ${ }^{56,59,61}$ one was comprehensive sex education, ${ }^{45}$ and one was a parent-youth relationship program. ${ }^{72}$ Three were implemented with only females, ${ }^{45,56,59}$ and two with mixed sexes. ${ }^{61,72}$ Four of these programs were implemented in a clinic setting, ${ }^{45,56,59,61}$ and one was implemented primarily in the home. ${ }^{72}$ Clearly more work is needed to develop effective STI-prevention strategies.

\section{Programs with impacts on sexual activity and contraceptive use}

Many more program evaluations measured impacts on key sexual or contraceptive-use behavioral determinants of teen pregnancies or STIs than of teen births or STIs. Programs that have impacts on both sexual activity and some measure of contraceptive use (including condom use) may be particularly effective at preventing early pregnancies and/or STIs. We examined which programs measured and had an impact on both a sexual activity outcome and a contraception outcome. Our review identified 72 program evaluations that measured both sexual activity and contraceptive or condom use; of these, 35 had consistent impacts or mixed findings on either sexual activity, contraception, or both. Of these, 15 program evaluations showed effectiveness at reducing at least one sexual activity outcome and at increasing at least one condom- or contraceptive-use outcome (including ten that had consistent impacts for both categories of outcomes ${ }^{38,39,44,45,47,49,50,52,53,58,71}$ and five that were mixed for one or both outcomes). ${ }^{34,42,48,61,63}$ Interestingly, two of these 15 programs were also effective at reducing pregnancies or births (including one with consistent impacts ${ }^{58}$ and one that had mixed findings across follow-ups), ${ }^{44}$ and two found consistent impacts on STIs. ${ }^{45,61}$ The majority (ten) of these 15 programs were comprehensive sex-education programs, ${ }^{34,38,39,42,44,45,47-50}$ but there were also three clinic-based programs, ${ }^{52,53,58,61}$ one parent-youth relationship program, ${ }^{71}$ and one youth-development program. ${ }^{63}$ These programs were implemented in school, ${ }^{34,48-50}$ community, ${ }^{39,44,45,52,53,58,61,63}$ clinic, ${ }^{38,42,44,48,63}$ home, ${ }^{42,71}$ and juvenile drug-center settings, ${ }^{47}$ and with a variety of age-groups. They were mostly shorter in duration, with eleven lasting less than 6 months and four longer than 6 months. Ten of these 15 effective programs were implemented with both sexes, one was male only, and four were female only. Again, we need to learn more about the less transparent elements of programs to understand the common elements that result in effectiveness across such a diverse body of interventions.

\section{Discussion}

We identified more than 100 rigorous random-assignment evaluations of sexual and reproductive health programs for this study, including a variety of program approaches, settings, and target populations. Two of the five programs approaches that we reviewed - parent-youth relationship programs and clinic-based approaches - were particularly effective at influencing the sexual and reproductive health outcomes that they targeted among teens. For example, more than three-quarters (nine of eleven) evaluated parent-teen relationship programs were effective for at least one outcome or population (described as "found to work" or "mixed"). In addition, several other effective programs incorporated parent-involvement components. These findings reflect the important role that parent-teen relationships, parental monitoring, and parent-teen communication play in influencing adolescent sexual and reproductive health behaviors. ${ }^{79}$

As a whole, clinic-based program approaches were also effective. Almost two-thirds of these program evaluations (nine of 14 reviewed program evaluations) were effective for at least one outcome or population. Several of these programs demonstrate the effectiveness of incorporating oneon-one components (often in combination with group-based or video sessions), particularly for increasing contraceptive use. Future research should assess the role of clinic-based approaches for reaching older teens, especially because more than two-thirds of teen births occur to women aged 18-19 years, most of whom are not connected to schools.

Although somewhat less consistently effective than the two aforementioned types of programs, about half of the youth-development programs were identified as effective. Those that were effective highlight the potential role of community service-learning approaches and often multicomponent programs that focus not only on adolescent reproductive health but other measures of well-being, including educational outcomes. ${ }^{80}$

Finally, though less effective than other types of programs, this review also identified a number of abstinence- and comprehensive sex-education programs that had impacts on sexual and reproductive health behaviors or outcomes. About a third of abstinence-based program evaluations found behavioral impacts (five of 14 studies reviewed received a "worked" or "mixed" categorization). Although low, this represents an increase from previous studies that documented 


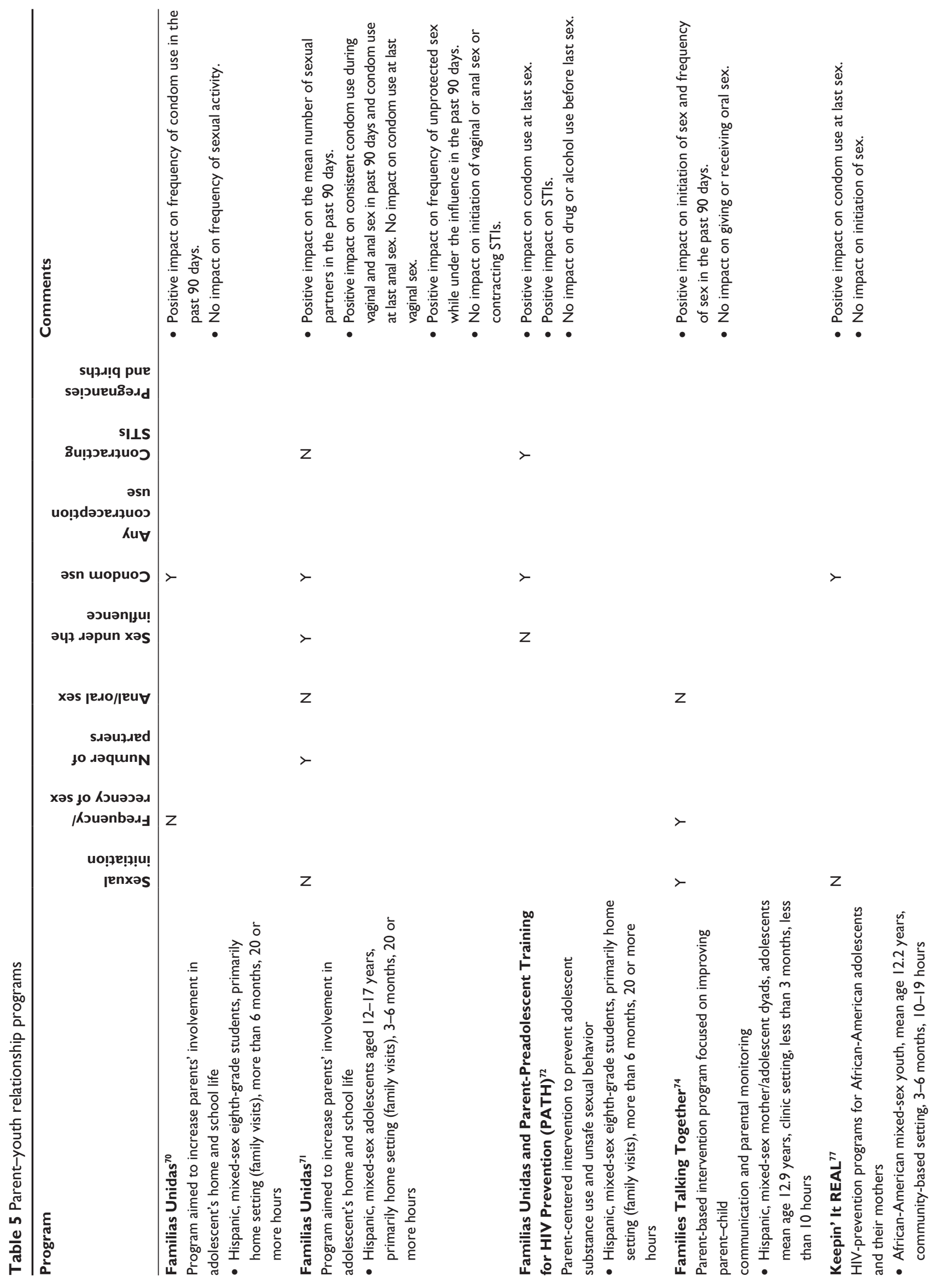



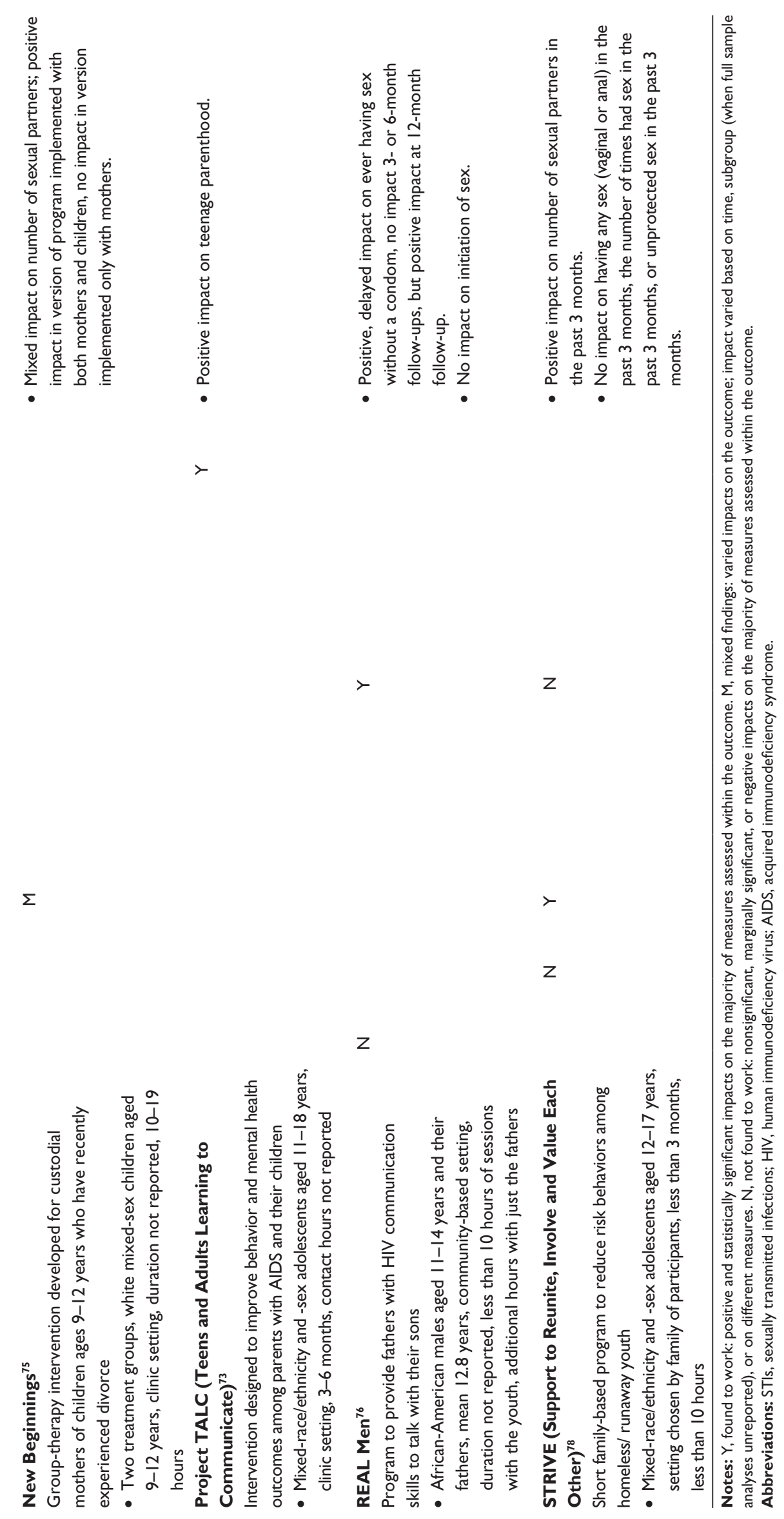
limited or no effective abstinence-education programs. ${ }^{81,82}$ Not surprisingly, the effective abstinence-education programs were most likely to impact sexual initiation or activity. ${ }^{24-26,28}$ However, our review also identified other programs that were effective at delaying sexual initiation (ten total), including six comprehensive sex-education programs (that often focus on both abstinence and condom use or contraceptive use), ${ }^{29,31,34,37,38,46}$ three youth-development programs, ${ }^{63,67,69}$ and one parent-child relationship program. ${ }^{74}$ Notably, although many more effective comprehensive sex-education programs were identified than abstinence-only programs, their rate of effectiveness (21 of 47 comprehensive sex-education evaluations reviewed) was similar to that of abstinence-education programs. These findings highlight the need to identify key implementation components that are particularly effective for improving sexual and reproductive health outcomes across program approaches. In fact, many of the programs that were not effective (listed in Table S1) included components that were similar to the effective programs (in Tables 1-5), which suggests that program implementation may be as important as program content for improving outcomes.

Some research has identified important characteristics of program implementation that are particularly effective for sexual and reproductive health programs. Kirby ${ }^{82}$ identified several key characteristics of effective curriculum teenpregnancy prevention programs, including clearly identifying health goals and the behavioral and psychosocial risk and protective factors leading to those goals during the programdevelopment stage; incorporating activities, instructional methods and messages that are relevant to the youth's culture, age, and sexual behavior; securing community support for the program; effectively training, monitoring, and supporting facilitators; and implementing programs with fidelity.

\section{Recommendations for the future}

Although this review identified 103 rigorous evaluations of sexual and reproductive health programs, future research and implementation evaluations can expand the evidence base in this area. First, replication is needed. Ideally, programs would impact behavior across replications in order to be designated as evidence-based; however, relatively few programs have been replicated and tested. Fifteen of the programs included in this review were evaluated more than once (this includes five evaluations of the comprehensive sex education program Be Proud! Be Responsible!). However, many of these were implemented with a different target population, setting, or location, so they did not necessarily confirm or contradict earlier findings. Programs that directly impact teen pregnancies and STIs - and their key determinants (including those with impacts on both sexual activity and contraceptive use) - are particularly important for further replications. Our review particularly highlights these programs.

Second, programs need to be updated. Several of the evaluations were of programs that were designed and implemented more than a decade ago. As a result, the activities and messages may be somewhat outdated for current populations of teens, ${ }^{22}$ and may require on-the-ground adaptations to make them relevant for race and ethnic minority populations. ${ }^{21}$ Third, we need a better understanding of how effective programs work. Since many of the effective programs had components similar to those with no impacts, future research can help identify what aspects of programs - such as implementation quality or staffing - are linked to stronger program impacts. Fourth, rigorous evaluation of promising programs is needed, including those that have been evaluated with quasiexperimental approaches and pre/posttest studies. Of particular interest are programs with impacts on contraceptive outcomes and those that are effective with older teens, who have the highest rates of teen pregnancy and STIs. Practitioner groups have highlighted the importance of hormonal and long-acting methods for pregnancy prevention and dual-method use for preventing pregnancy and STIs, but we found very few evaluations of these outcomes. Finally, although we include strong review criteria (requiring a random-assignment evaluation design with an intent-to-treat approach), we did not rate programs based on the quality of the evaluations. Future research should consider characteristics of evaluation quality, including baseline equivalence and attrition. ${ }^{20}$

\section{Conclusion}

This review examined rigorous evaluations of sexual and reproductive health programs, and identified programs with impacts using a variety of approaches. Current federal initiatives to scale up evidence-based programs can help increase the likelihood that high-risk youth will receive programming that will help them reduce high rates of pregnancy and STIs in the US. Meanwhile, new programs and approaches should be evaluated to continue to expand the evidence base into the future.

\section{Acknowledgments}

This research was funded by a grant from the Alexander and Margaret Stuart Trust and the Edna McConnell Clark Foundation.

\section{Disclosure}

The authors report no conflicts of interest in this work. 


\section{References}

1. Martin JA, Hamilton BE, Osterman MJ. Births in the United States, 2013. Hyattsville (MD): Centers for Disease Control and Prevention; 2014.

2. United Nations. 2012 Demographic Yearbook. New York: UN; 2013.

3. Mosher WD, Jones J, Abma JC. Intended and Unintended Births in the United States: 1982-2010. Hyattsville (MD): National Center for Health Statistics; 2012.

4. Martin JA, Hamilton BE, Osterman MJK, Curtin SC, Mathews TJ. Births: Final Data for 2012. Hyattsville (MD): National Center for Health Statistics; 2013.

5. Hoffman SD, Maynard RA. Kids Having Kids: Economic Costs and Social Consequences of Teen Pregnancy. 2nd ed. Washington: Urban Institute; 2008.

6. Martinez G, Copen CE, Abma JC. Teenagers in the United States: Sexual Activity, Contraceptive Use, and Childbearing -2006-2010 National Survey of Family Growth. Washington: National Center for Health Statistics; 2011.

7. Moore K, Sacks V, Manlove J, Sawhill I. "What If" You Earned a Diploma and Delayed Parenthood? Bethesda (MD): Child Trends; 2014.

8. Hamilton BE, Martin JA, Osterman MJ, Curtin SC. Births: Preliminary Data for 2013. Hyattsville (MD): National Center for Health Statistics; 2014.

9. Klerman JA. Another Chance: Preventing Additional Births to Teen Mothers. Washington: National Campaign to Prevent Teen Pregnancy; 2004.

10. National Campaign to Prevent Teen and Unplanned Pregnancy. Counting it Up: The Public Costs of Teen Childbearing. Washington: National Campaign to Prevent Teen and Unplanned Pregnancy; 2011.

11. Centers for Disease Control and Prevention. CDC fact sheet: Incidence, prevalence, and cost of sexually transmitted infections in the United States. 2013. Available from: http://www.cdc.gov/std/stats/STI-Estimates-Fact-Sheet-Feb-2013.pdf. Accessed August 20, 2013.

12. Forhan SE, Gottlieb SL, Sternberg MR, et al. Prevalence of sexually transmitted infections among female adolescents aged 14 to 19 in the United States. Pediatrics. 2009;124(6):1505-1512.

13. Wildsmith E, Barry M, Vaughn B, Manlove J. Adolescent Health Highlight: Sexually Transmitted Diseases (STDs). Bethesda (MD): Child Trends; 2013.

14. Centers for Disease Control and Prevention. Youth Risk Behavior Surveillance - United States, 2013. Atlanta: US Department of Health and Human Services; 2014.

15. Darroch JE, Frost JJ, Singh S. Differences in teenage pregnancy rates among five developed countries: the roles of sexual activity and contraceptive use. Fam Plann Perspect. 2001;33(6):244-250, 281.

16. Jones J, Mosher W, Daniels K. Current Contraceptive Use in the United States, 2006-2010, and Changes in Patterns of Use since 1995. Hyattsville (MD): National Center for Health Statistics; 2012.

17. Thomas A. Three strategies to prevent unintended pregnancy. J Policy Anal Manage. 2012;31(2):280-311.

18. Albert B. With One Voice 2012: America's Adults and Teens Sound Off about Teen Pregnancy. Washington: National Campaign to Prevent Teen and Unplanned Pregnancy; 2012.

19. National Campaign to Prevent Teen and Unplanned Pregnancy. Federal Funding Stream for Teen Pregnancy Prevention. Washington: National Campaign to Prevent Teen and Unplanned Pregnancy;2014.

20. Office of Adolescent Health. TTP Resource Center: Evidencebased programs. 2014. Available from: http://www.hhs.gov/ash/oah/ oah-initiatives/teen_pregnancy/db. Accessed May 14, 2014.

21. Scott ME, Berger A, Caal S, Hickman S, Moore K. Preventing Teen Pregnancy among Latinos: Recommendations from Research, Evaluation, and Practitioner Experience. Bethesda (MD): Child Trends; 2014.

22. Scott ME, Wallace I. State and tribal PREP performance measures: findings and implications for program improvement. Poster presented at: 2014 Teen Pregnancy Prevention Grantee Conference; June 4-6, 2014; Washington, DC.

23. Child Trends. About What Works (LINKS). Available from: http://www. childtrends.org/what-works. Accessed May 15, 2014.
24. Lieberman $\mathrm{L}, \mathrm{Su} \mathrm{H}$. Choosing the best program in communities committed to abstinence education. Sage Open. 2012;2(1):1-12.

25. Jemmott JB, Jemmott LS, Fong GT. Efficacy of a theory-based abstinence-only intervention over 24 months: a randomized controlled trial with young adolescents. Arch Pediatr Adolesc Med. 2010;164(2): $152-159$.

26. LaChausse RG. Evaluation of the Positive Prevention HIV/STD curriculum. Am J Health Educ. 2006;37(4):203-209.

27. Cabezón C, Vigil P, Rojas I, et al. Adolescent pregnancy prevention: an abstinence-centered randomized controlled intervention in a Chilean public high school. J Adolesc Health. 2005;36(1):64-69.

28. Vigil P, Riquelme R, Rivandeneira R, Klaus H. Effect of TeenSTAR, an abstinence-only sexual education program on adolescent sexual behavior. Poster presented at: North American Society for Pediatric and Adolescent Gynecology 19th Annual Clinical Meeting; November 15-19, 2005; New Orleans, LA.

29. Coyle KK, Kirby DB, Marín BV, Gómez CA, Gregorich SE. Draw the line/respect the line: a randomized trial of a middle school intervention to reduce sexual risk behaviors. Am J Public Health. 2004;95(5): 843-851.

30. Walker D, Gutierrez JP, Torres P, Bertozzi SM. HIV prevention in Mexican schools: prospective randomised evaluation of intervention. BMJ. 2006;332(7551):1189-1192.

31. Tortolero S, Markham C, Peskin MF, et al. It's Your Game: Keep It Real: delaying sexual behavior with an effective middle school program. $J$ Adolesc Health. 2010;46(2):169-179.

32. Markham CM, Tortolero SR, Peskin MF, et al. Sexual risk avoidance and sexual risk reduction interventions for middle school youth a randomized controlled trial. J Adolesc Health. 2012;50(3):279-288.

33. Markham CM, Peskin MF, Shegog R, et al. Behavioral and psychosocial effects of two middle school sexual health education programs at tenthgrade follow-up. J Adolesc Health. 2014;54(2):151-159.

34. Aarons SJ, Jenkins RR, Raine TR, et al. Postponing sexual intercourse among urban junior high school students - a randomized controlled evaluation. J Adolesc Health. 2000;27(4):236-247.

35. Coyle K, Basen-Engquist K, Kirby D, et al. Short-term impact of safer choices: a multicomponent, school-based HIV, other STD, and pregnancy prevention program. J Sch Health. 1999 1999;69(5):181-188.

36. Coyle K, Basen-Engquist K, Kirby D, et al. Safer choices: reducing teen pregnancy, HIV, and STDs. Public Health Rep. 2001;116 Suppl 1:82-93.

37. Grossman JM, Tracy AJ, Charmaraman L, Ceder I, Erkut S. Protective effects of middle school comprehensive sex education with family involvement. J Sch Health. 2014;84(11):739-747.

38. Sikkema KJ, Anderson ES, Kelly JA, et al. Outcomes of a randomized, controlled community-level HIV prevention intervention for adolescents in low-income housing developments. AIDS. 2005;19(14): 1509-1516.

39. St Lawrence JS, Brasfield TL, Jefferson KW, Alleyne E, O’Bannon RE, Shirley A. Cognitive behavioral intervention to reduce African American adolescents' risk for HIV infection. $J$ Consult Clin Psychol. 1995;63(2):221-237.

40. Stanton B, Li X, Galbraith J, Feigelman S, Kaljee L. Sexually transmitted diseases, human immunodeficiency virus, and pregnancy prevention: combined contraceptive practices among urban African-American early adolescents. Arch Pediatr Adolesc Med. 1996;150(1):17-24.

41. Stanton B, Li X, Ricardo I, Galbraith J, Feigelman S, Kaljee L. A randomized, controlled effectiveness trial of an AIDS prevention program for low-income African American youths. Arch Pediatr Adolesc Med. 1996;150(4):363-372.

42. Wu Y, Stanton BF, Galbraith J, et al. Sustaining and broadening intervention impact: a longitudinal randomized trial of 3 adolescent risk reduction approaches. Pediatrics. 2003;111(1):e32-e38.

43. Bryan AD, Schmiege SJ, Broaddus MR. HIV risk reduction among detained adolescents: a randomized controlled trial. Pediatrics. 2009;124(6):e1180-e1188.

44. DiClemente R, Wingood G, Harrington K, et al. Efficacy of an HIV prevention intervention for African American adolescent girls: a randomized controlled trial. JAMA. 2004;292(2):171-179. 
45. Jemmott JM, Jemmott LS, Braverman PK, Fong GT. HIV/STD risk reduction interventions for African American and Latino adolescent girls at an adolescent medicine clinic. Arch Pediatr Adolesc Med. 2005;159(5):440-449.

46. Eisen M, Zellman GL, McAlister AL. Evaluating the impact of a theory-based sexuality and contraceptive education program. Fam Plann Perspect. 1990;22(6):261-271.

47. St Lawrence JS, Crosby RA, Brasfield TL, O'Bannan RE 3rd. Reducing STD and HIV risk behavior of substance-dependent adolescents: a randomized controlled trial. J Consult Clin Psychol. 2002;70(4):1010-1021.

48. Villarruel A, Jemmott J, Jemmott L. A randomized controlled trial testing an HIV prevention intervention for Latino youth. Arch Pediatr Adolesc Med. 2006;160(8):772-777.

49. Jemmott JB 3rd, Jemmott LS, Fong GT. Reductions in HIV risk-associated sexual behaviors among black male adolescents: effects of an AIDS prevention intervention. Am J Public Health. 1992;82(3):372-377.

50. Jemmott JB 3rd, Jemmott LS, Fong GT, McCaffree K. Reducing HIV risk-associated sexual behavior among African-American adolescents: testing the generality of intervention effects. Am J Community Psychol. 1999;27(2):161-187.

51. Jemmott JBI, Jemmott LS, Fong GT, Morales KH. Effectiveness of an HIV/STD risk-reduction intervention for adolescents when implemented by community-based organizations: a cluster-randomized controlled trial. Am J Public Health. 2010;100(4):720-726.

52. Sieving RE, McMorris BJ, Beckman KJ, et al. Prime Time: 12-month sexual health outcomes of a clinic-based intervention to prevent pregnancy risk behaviors. J Adolesc Health. 2011;49(2):172-179.

53. Sieving RE, McRee A, Secor-Turner M, et al. Prime Time: long-term sexual health outcomes of a clinic-linked intervention. Perspect Sex Reprod Health. 2014;46(2):91-100.

54. Orr DP, Langefeld CD, Katz BP, Caine VA. Behavioral intervention to increase condom use among high-risk female adolescents. $J$ Pediatr. 1996;128(2):288-295.

55. DiClemente R, Wingood G, Rose E, et al. Efficacy of sexual transmitted disease/human immunodeficiency virus sexual risk-reduction intervention for African American adolescent females seeking sexual health services. Arch Pediatr Adolesc Med. 2009;163(12): $1112-1121$.

56. Champion JD, Collins JL. Comparison of a theory-based (AIDS Risk Reduction Model) cognitive behavioral intervention versus enhanced counseling for abused ethnic minority adolescent women on infection with sexually transmitted infection: results of a randomized controlled trial. Int J Nurs Stud. 2012;49(2):138-150.

57. Roye C, Perlmutter Silverman P, Kraus B. A brief, low cost, theorybased intervention to promote duel method use by black and Latina female adolescents: a randomized clinical trial. Health Educat Behav. 2007;34(4):608-621.

58. Morrison-Beedy D, Jones SH, Xia Y, Tu X, Crean HF, Carey MP. Reducing sexual risk behavior in adolescent girls: results from a randomized controlled trial. $J$ Adolesc Health. 2013;52(3):314-321.

59. Downs JS, Murray PJ, Bruine de Bruin W, Penrose J, Palmgren C, Fischhoff B. Interactive video behavioral intervention to reduce adolescent females' STD risk: a randomized controlled trial. Soc Sci Med. 2004;59(8):1561-1572.

60. Danielson R, Marcy S, Plunkett A, Wiest W, Greenlick MR. Reproductive health counseling for young men: what does it do? Fam Plann Perspect. 1990;22(3):115-121.

61. Kamb ML, Fishbein M, Douglas JM Jr, et al. Efficacy of riskreduction counseling to prevent human immunodeficiency virus and sexually transmitted diseases: a randomized controlled trial. JAMA. 1998;280(13):1161-1167.

62. Philliber S, Kaye J, Herrling S. The National Evaluation of the Children's Aid Society Carrera-Model Program to Prevent Teen Pregnancy. Accord (NY): Philliber Research Associates; 2001.
63. Philliber S, Kaye JW, Herrling S, West E. Preventing pregnancy and improving health care access among teenagers: an evaluation of the Children's Aid Society-Carrera Program. Perspect Sex Reprod Health. 2002;34(5):244-251.

64. Hahn A, Leavitt T, Aaron P. Evaluation of the Quantum Opportunities Program: Did the Program Work? Waltham (MA): Heller Graduate School, Brandeis University; 1994.

65. Allen JP, Philliber S, Herrling S, Kuperminc GP. Preventing teen pregnancy and academic failure: experimental evaluation of a developmentally based approach. Child Dev. 1997;68(4):729-742.

66. Philliber S, Allen JP. Life options and community service: teen outreach program. In: Miller BC, Card JJ, Paikoff RL, Perterson JL, editors. Preventing Adolescent Pregnancy: Model Programs and Evaluations. Newbury Park (CA): Sage; 1992.

67. O'Donnell L, Stueve A, O'Donnell C, et al. Long-term reductions in sexual initiation and sexual activity among urban middle schoolers in the reach for health service learning program. $J$ Adolesc Health. 2002;31(1):93-100.

68. McBride D, Gienapp A. Using randomized designs to evaluate client-centered programs to prevent adolescent pregnancy. Fam Plann Perspect. 2000;32(5):227-235.

69. Beets MW, Flay BR, Vuchinich RA, et al. Use of a social and character development program to prevent substance use, violent behaviors, and sexual activity among elementary-school students in Hawaii. Am J Public Health. 2009;99(8):1438-1445.

70. Pantin H, Guillermo P, Lopez B, et al. A randomized controlled trial of Familias Unidas for Hispanic adolescents with behavior problems. Psychosom Med. 2009;71(9):987-995.

71. Prado G, Pantin H, Huang S, et al. Effects of a family intervention in reducing HIV risk behaviors among high-risk Hispanic adolescents. Arch Pediatr Adolesc Med. 2012;166(2):127-133.

72. Prado G, Pantin H, Briones E, et al. A randomized controlled trial of a parent-centered intervention in preventing substance use and HIV risk behaviors in Hispanic adolescents. J Consult Clin Psychol. 2007;75(6): 914-926.

73. Rotheram-Borus MJ, Lee M, Leonard N, et al. Four-year behavioral outcomes of an intervention for parents living with HIV and their adolescent children. AIDS. 2003;17(8):1217-1225.

74. Guilamo-Ramos V, Bouris A, Jaccard J, Gonzalez B, McCoy W, Aranda D. A parent-based intervention to reduce sexual risk behavior in early adolescence: building alliances between physicians, social workers and parents. J Adolesc Health. 2011;48(2):159-163.

75. Wolchik SA, Sandler IN, Millsap RE, et al. Six-year follow-up of preventive interventions for children of divorce. JAMA. 2002;288(15): 1874-1881.

76. Dilorio C, McCarty F, Resnicow K, Lehr S, Denzmore P. REAL men: a group-randomized trial of an HIV prevention intervention for adolescent boys. Am J Public Health. 2007;97(6):1084-1089.

77. Dilorio C, Resnicow K, McCarty F. Keepin' it REAL!: results of a mother-adolescent HIV prevention program. Nurs Res. 2006;55(1): $43-51$.

78. Milburn NG, Iribarren FJ, Rice E, et al. A family intervention to reduce sexual risk behavior, substance use, and delinquency among newly homeless youth. J Adolesc Health. 2012;50(4):358-364.

79. Miller B, Benson B, Galbraith K. Family relationships and adolescent pregnancy risk: a research synthesis. Dev Rev. 2001;21(1):1-38.

80. Ling T, Moore KA. What Works for Education: Lessons from Experimental Evaluations of Programs and Social Interventions to Enhance Educational Outcomes. Washington: Child Trends; 2008.

81. Ball V, Moore K. What Works for Adolescent Reproductive Health: Lessons from Experimental Evaluations of Programs and Interventions. Washington: Child Trends; 2008.

82. Kirby D. Emerging Answers 2007: Research Findings on Programs to Reduce Teen Pregnancy and Sexually Transmitted Diseases. Washington: National Campaign to Prevent Teen and Unplanned Pregnancy; 2007. 


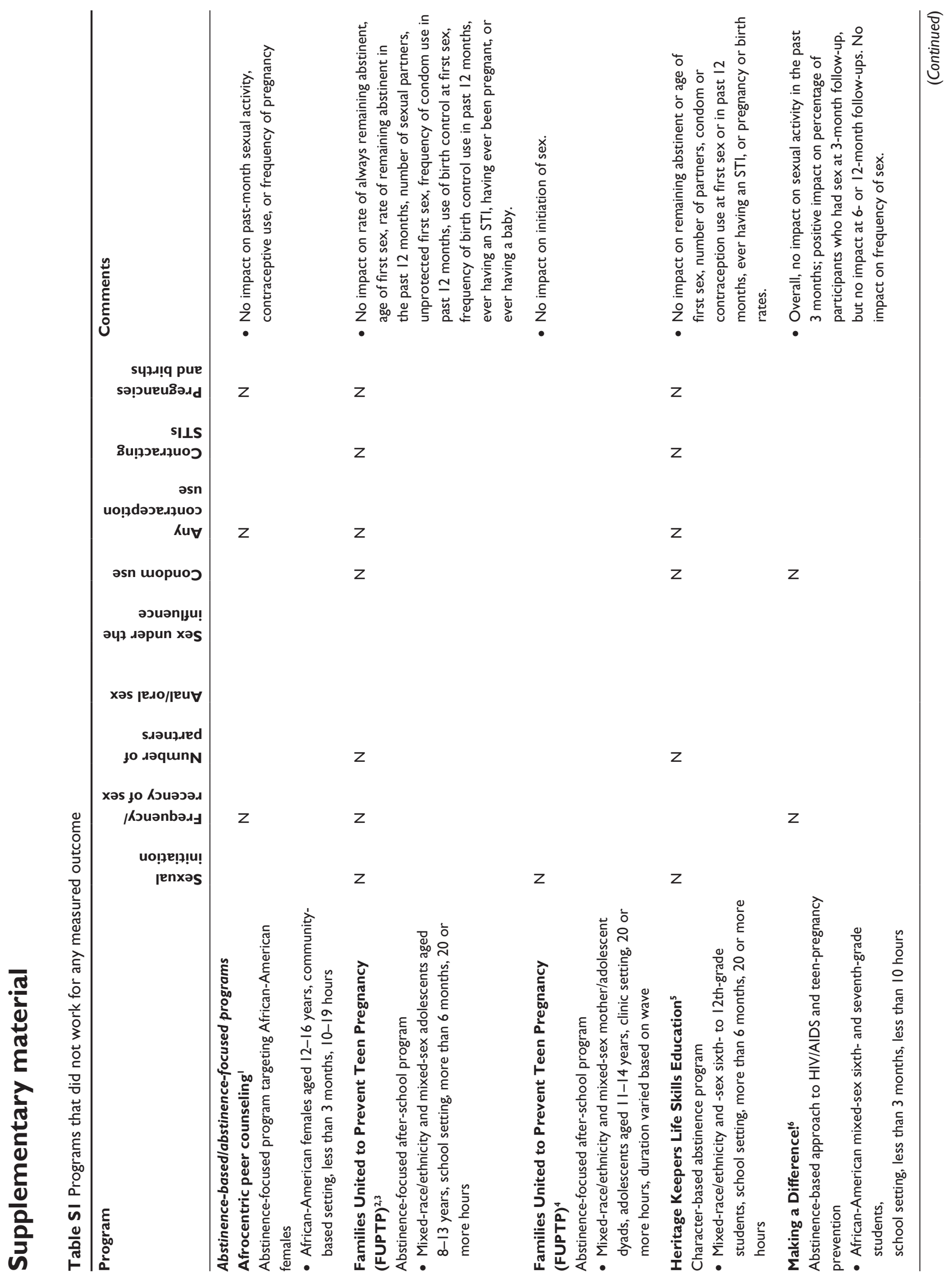




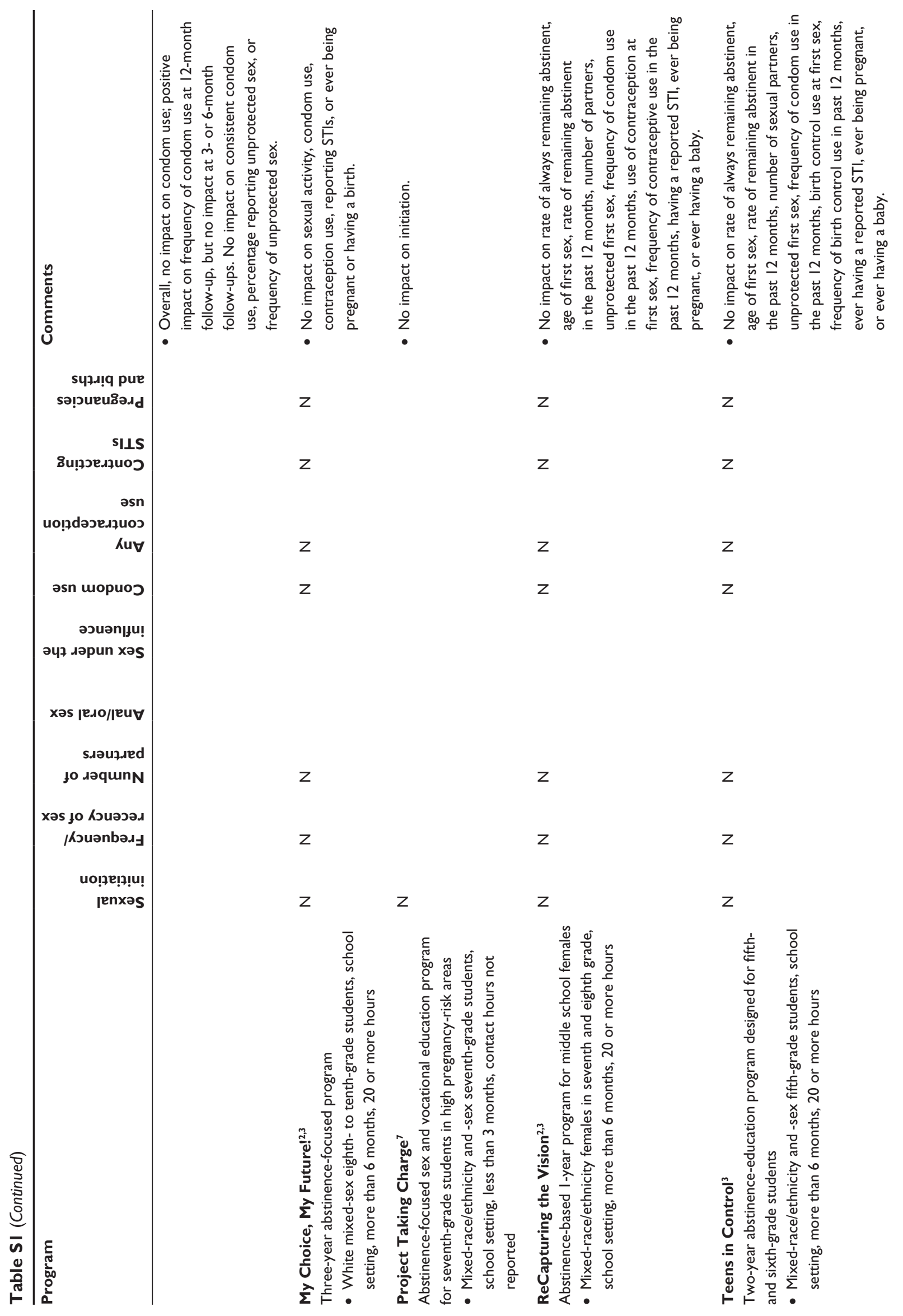



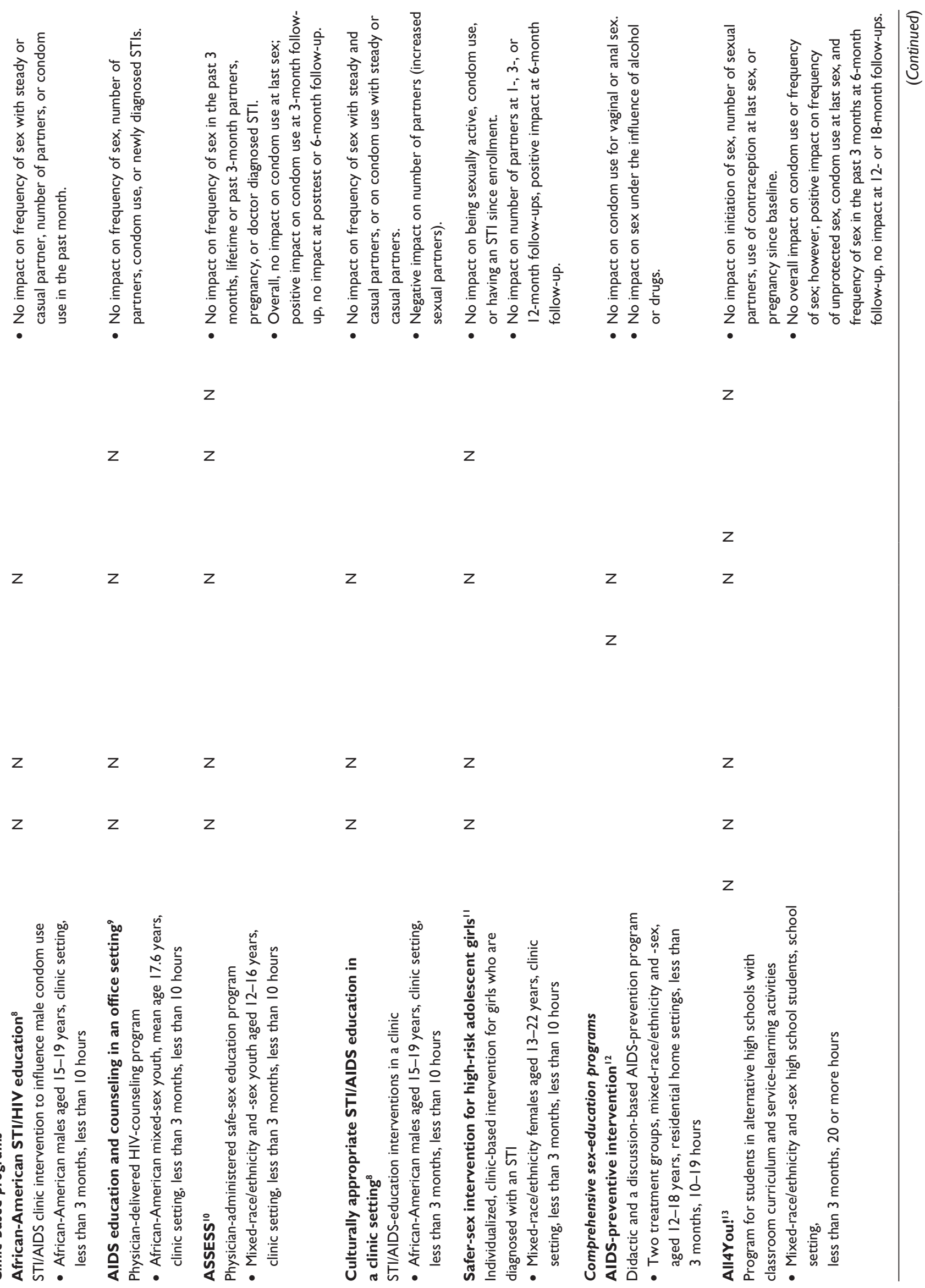


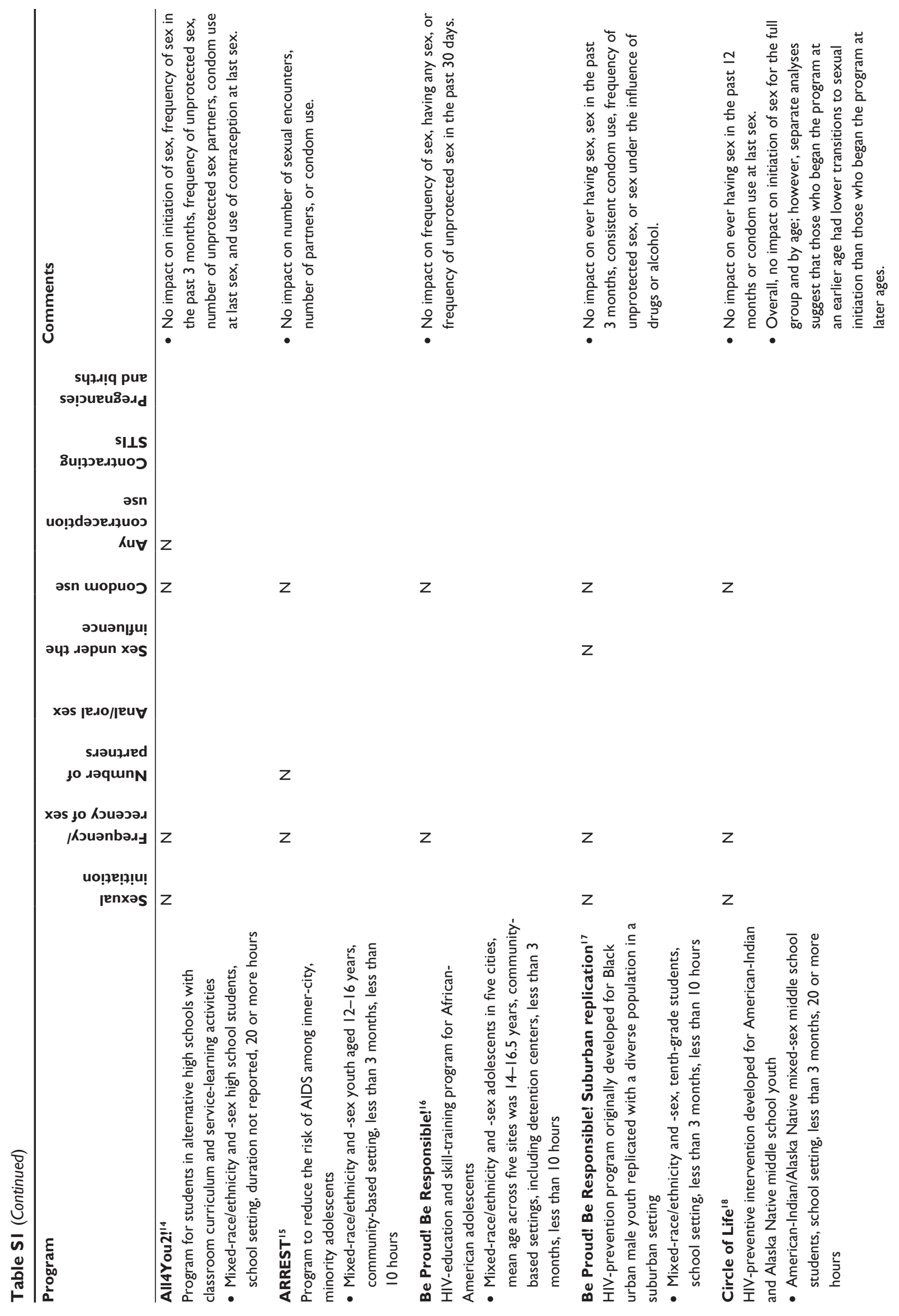



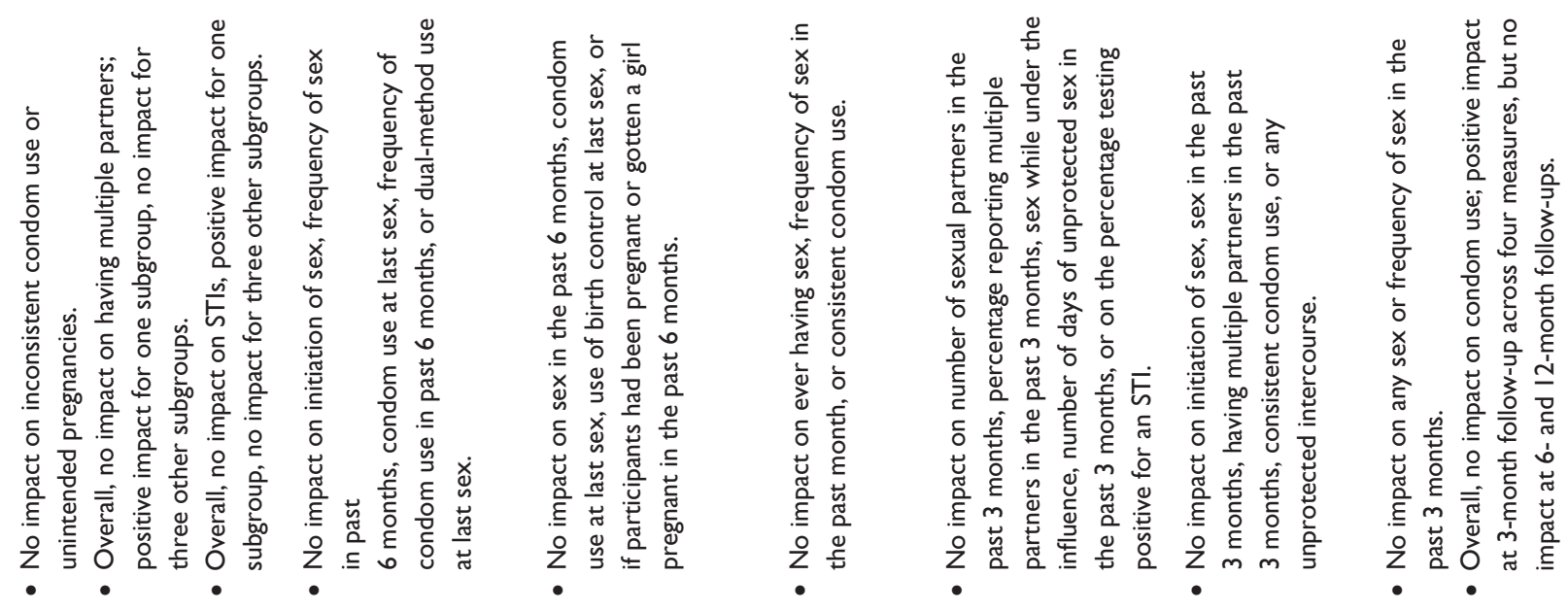

Z

Z

Z<smiles>[3H]</smiles>

Z

$z \quad z$

Z

z $\quad$ z

Z

Z

Z

Z

z

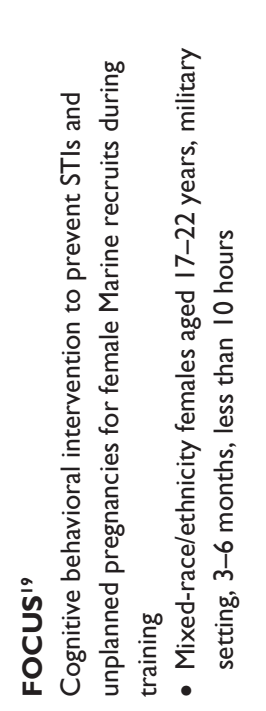

Z

Z

$\begin{array}{ccc}\text { z } & \text { z } \\ z & z & z \\ z & z\end{array}$
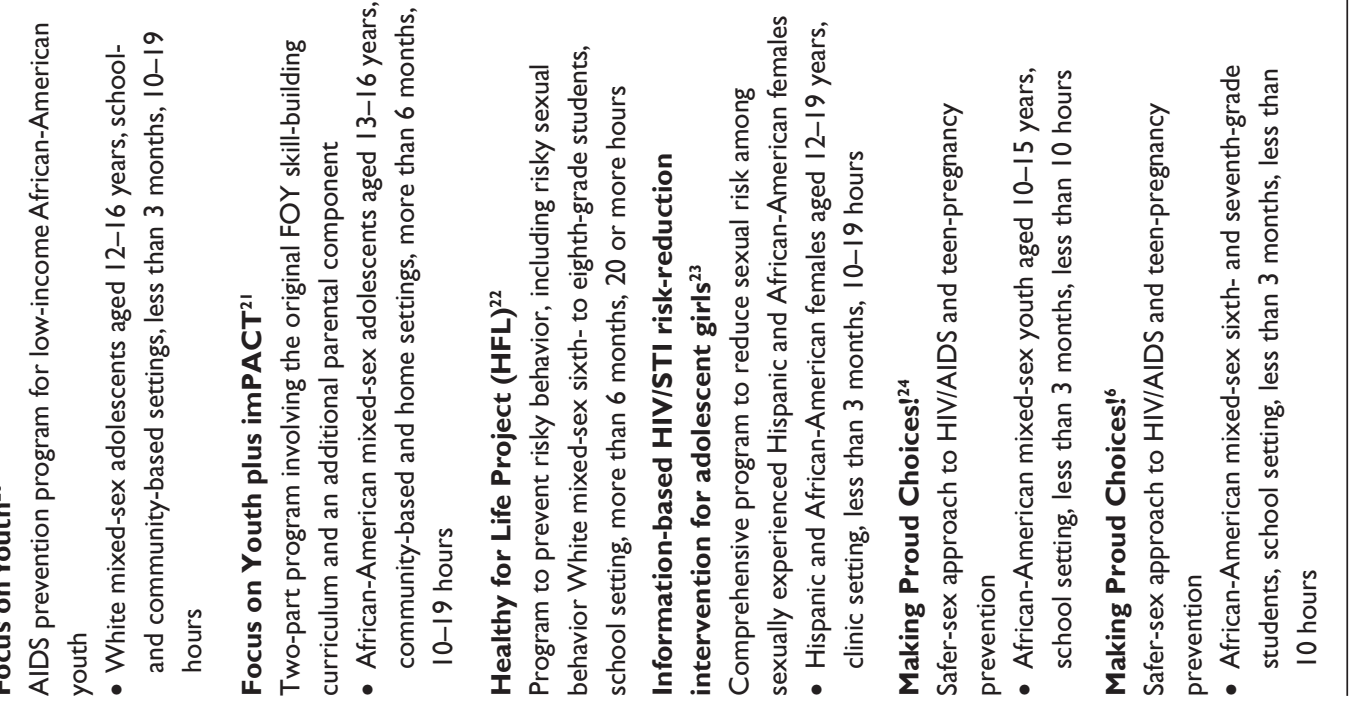


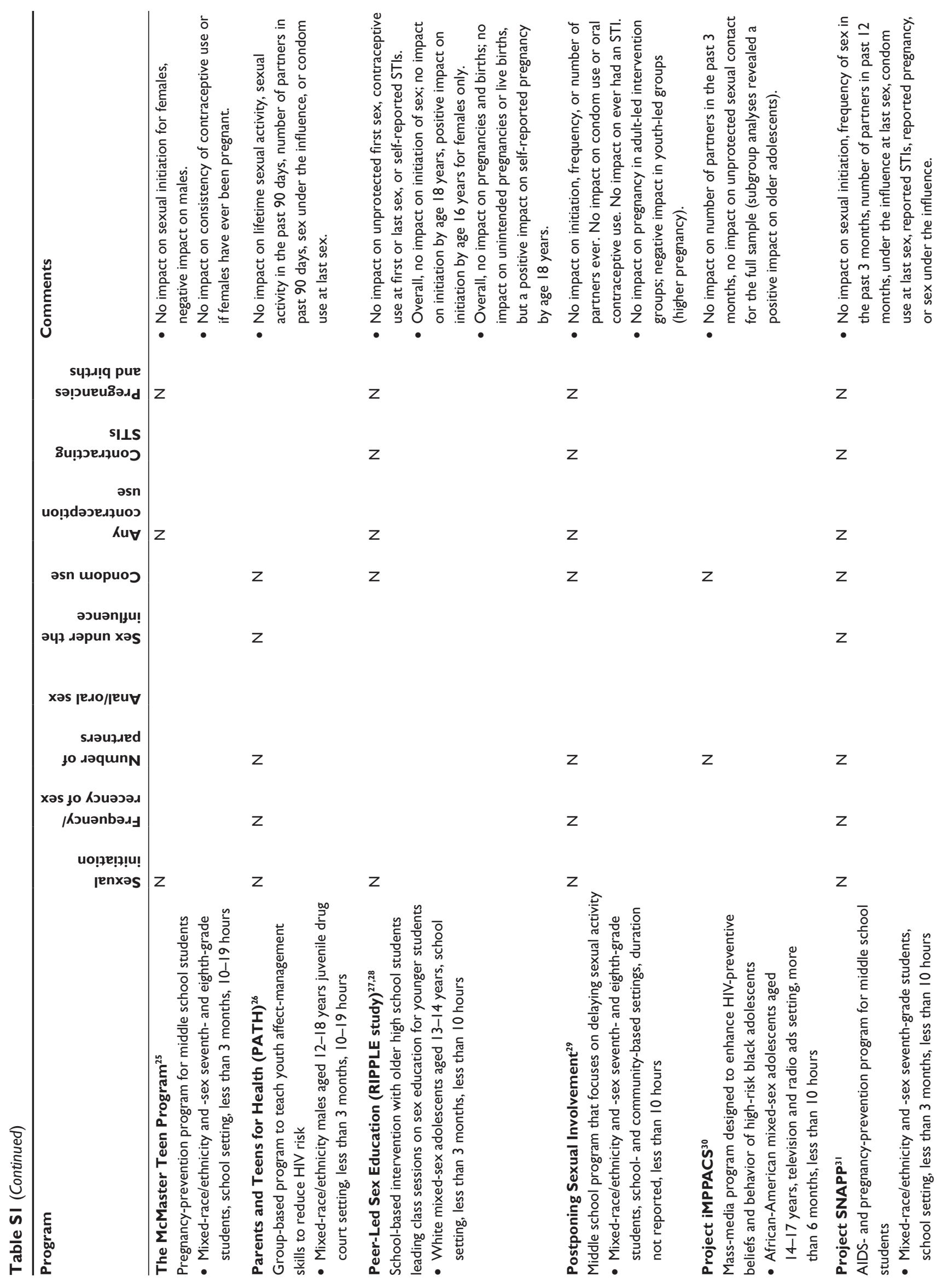



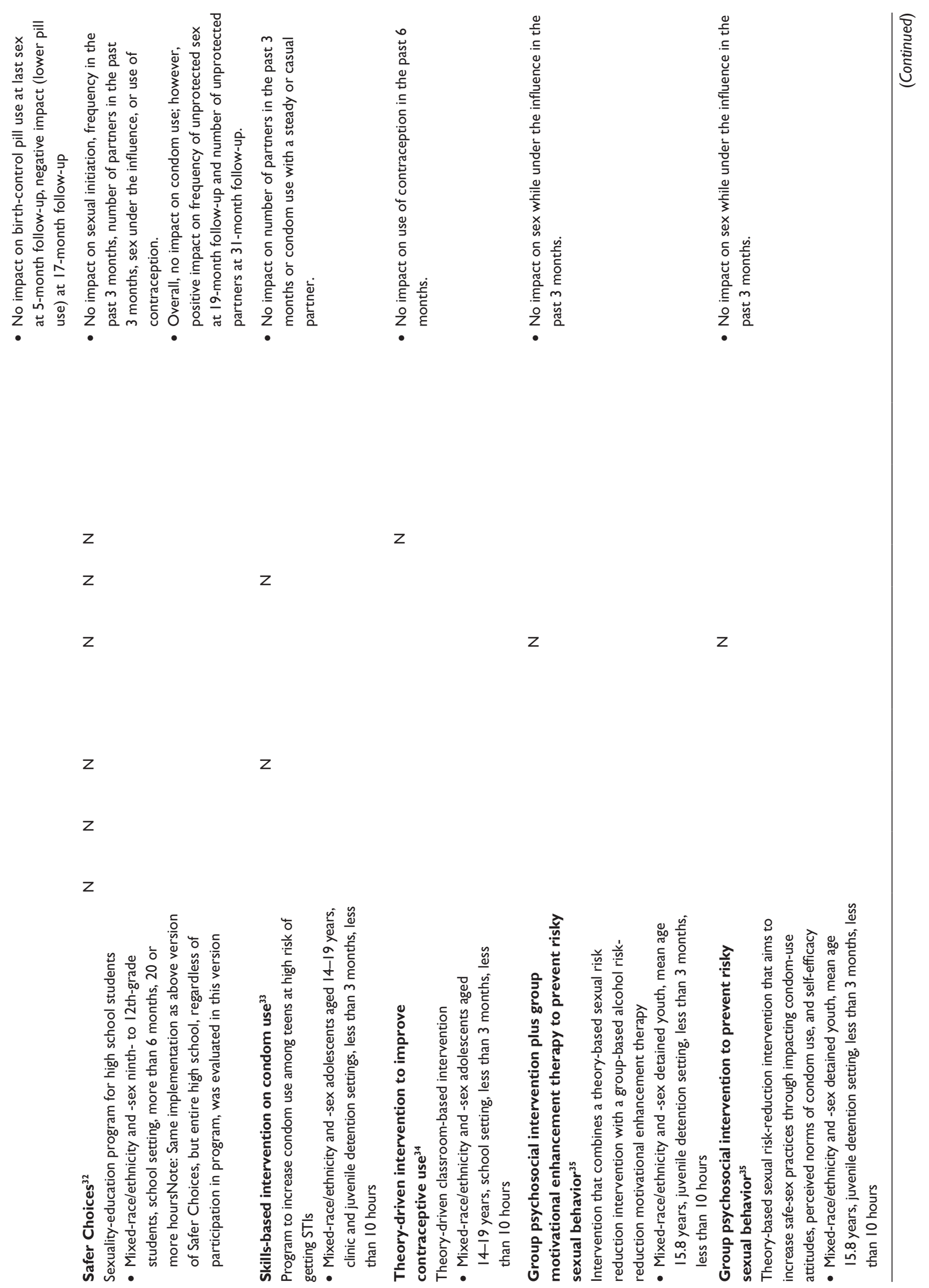


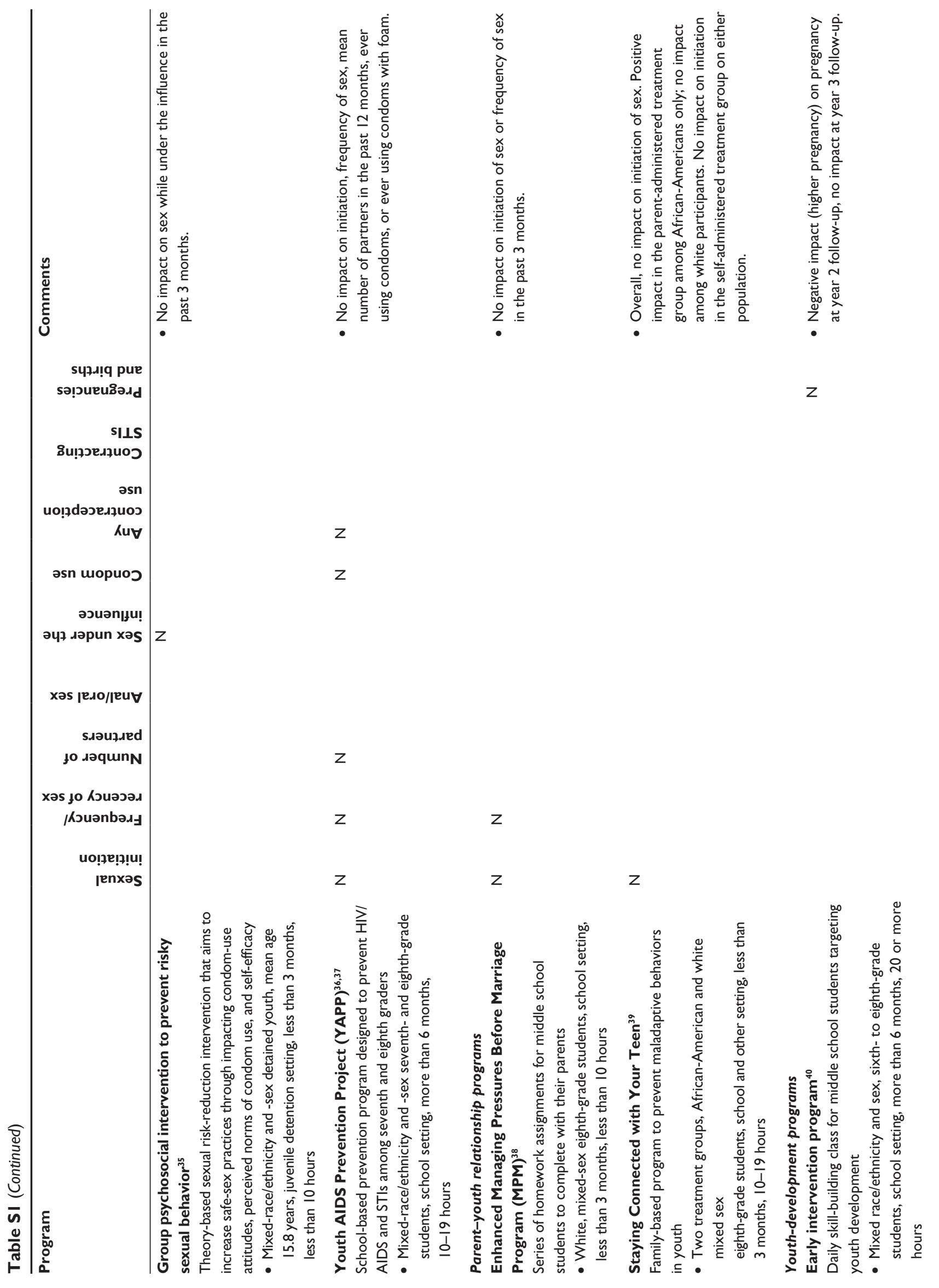




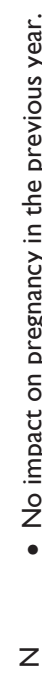
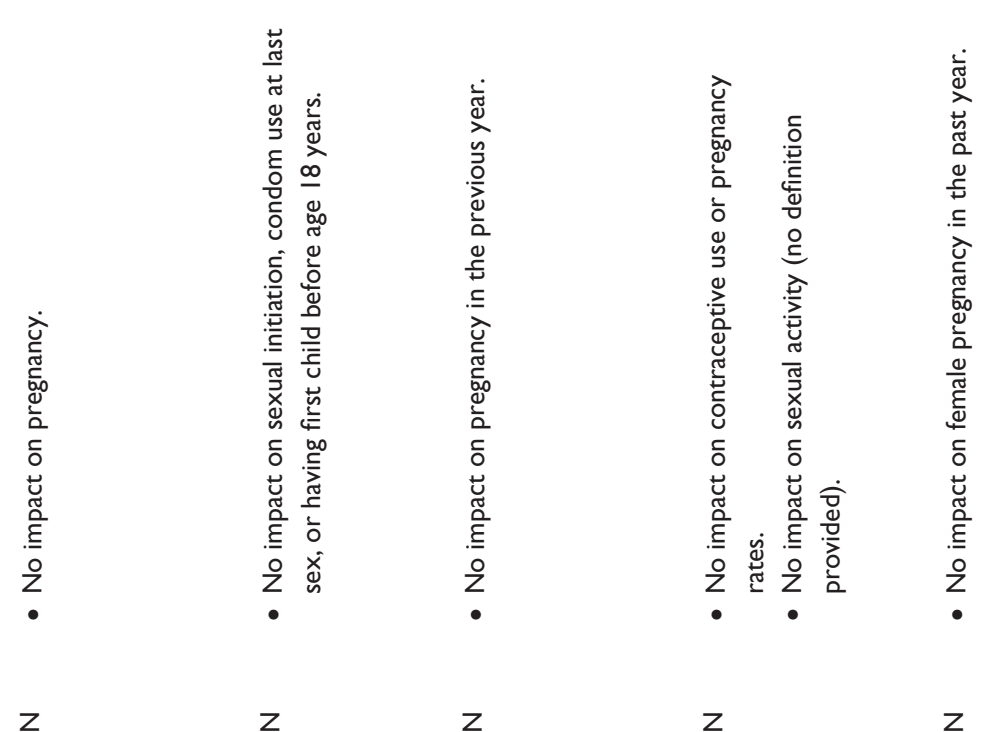

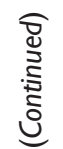

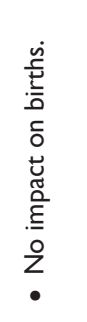

Z

Z

Z

Z

Z

Z

Z

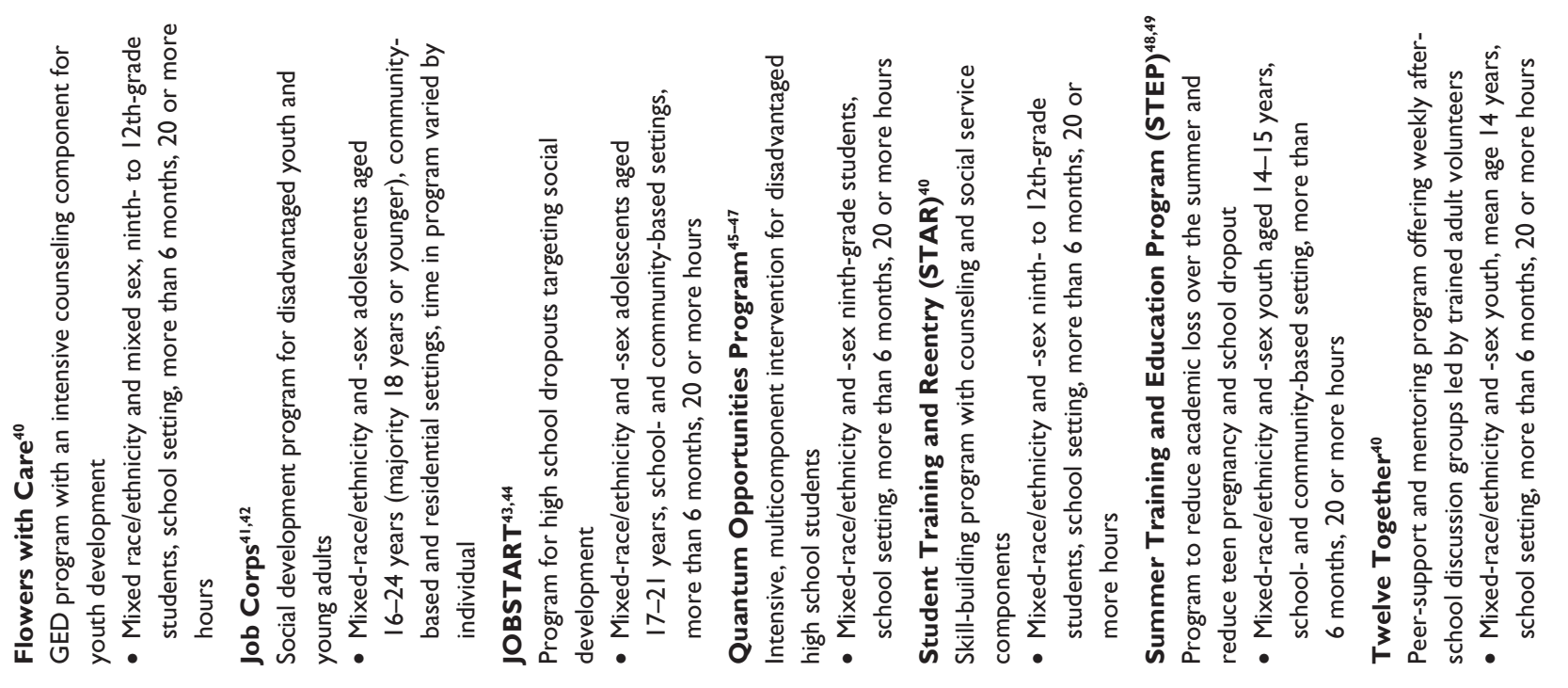




\section{References}

1. Ferguson SL. Peer counseling in a culturally specific adolescent pregnancy prevention program. $J$ Health Care Poor Underserved. 1998;9(3):322-340.

2. Trenholm C, Devaney B, Fortson K, Clark M, Quay L, Wheeler J. Impacts of abstinence education on teen sexual activity, risk of pregnancy, and risk of sexually transmitted diseases. J Policy Anal Manage. 2008;27(2):255-276.

3. Trenholm C, Devaney B, Fortson K, Quay L, Wheeler J, Clark M. Impact of Four Title V, Section 510 Abstinence Education Programs. Princeton (NJ): Mathematica Policy Research; 2007.

4. Greene VL, Monahan DJ, Ditmar M, Roloson T. Effectiveness of an abstinence-only intervention sited in neighborhood community centers. J Child Poverty. 2011;17(1):111-124.

5. Clark MA, Trenholm C, Devaney B, Wheeler J, Quay L. Impacts of the Heritage Keepers Life Skills Education Component. Princeton (NJ): Mathematica Policy Research; 2007.

6. Jemmott JB 3rd, Jemmott LS, Fong GT. Abstinence and safer sex: HIV risk-reduction interventions for African American adolescents. A randomized controlled trial. JAMA. 1998;279(19):1529-1536.

7. Jorgensen S. Project Taking Charge: an evaluation of an adolescent pregnancy prevention program. Fam Relat. 1991;40(4):373-380.

8. DeLamater J, Wagstaff DA, Havens KK. The impact of a culturally appropriate STD/AIDS education intervention on black male adolescents' sexual and condom use behavior. Health Educ Behav. 2000;27(4):454-470.

9. Mansfield CJ, Conroy ME, Emans SJ, Woods ER. A pilot study of AIDS education and counseling of high-risk adolescents in an office setting. J Adolesc Health. 1993;14(2):115-119.

10. Boekeloo BO, Schamus LA, Simmens SJ, Cheng TL, O'Connor K, D'Angelo LJ. A STD/HIV prevention trial among adolescents in managed care. Pediatrics. 1999;103(1):107-115.

11. Shrier LA, Ancheta R, Goodman E, Chiou V, Lyden MR, Emans SJ. Randomized controlled trial of a safer sex intervention for high-risk adolescent girls. Arch Pediatr Adolesc Med. 2001;155(1):73-79.

12. Slonim-Nevo V, Auslander WF, Ozawa MN, Jung KG. The long-term impact of AIDS-preventive interventions for delinquent and abused adolescents. Adolescence. 1996;31(122):409-421.

13. Coyle KK, Kirby DB, Robin LE, Banspach SW, Baumler E, Glassman JR. All4You! A randomized trial of an HIV, other STDs, and pregnancy prevention intervention for alternative school students. AIDS Educ Prev. 2006;18(3):187-203.

14. Coyle KK, Glassman JR, Franks HM, Campe SM, Denner J, Lepore GM. Interventions to reduce sexual risk behaviors among youth in alternative schools: a randomized controlled trial. J Adolesc Health. 2013;53(1):68-78.

15. Kipke MD, Boyer C, Hein K. An evaluation of an AIDS risk reduction education and skills training (ARREST) program. $J$ Adolesc Health. 1993;14(7):533-539.

16. Kennedy MG, Mizuno Y, Hoffman R, Baume C, Strand J. The effect of tailoring a model HIV prevention program for local adolescent target audiences. AIDS Educ Prev. 2000;12(3):225-238.

17. Borawski EA, Trapl ES, Adams-Tufts K, Hayman LL, Goodwin MA, Lovegreen LD. Taking Be Proud! Be Responsible! to the suburbs: a replication study. Perspect Sex Reprod Health. 2009;41(1): $12-22$.

18. Kaufman CE, Whitesell NR, Keane EM, et al. Effectiveness of Circle of Life, an HIV-preventive intervention for American Indian middle school youths: a group randomized trial in a Northern Plains tribe. Am J Public Health. 2014;104(6):e106-e112.

19. Boyer CB, Shafer M, Shaffer RA, et al. Evaluation of a cognitivebehavioral, group, randomized controlled intervention trial to prevent sexually transmitted infections and unintended pregnancies in young women. Prev Med. 2005;40(4):420-431.

20. Stanton B, Harris C, Cottrell L, et al. Trial of an urban adolescent sexual risk-reduction intervention for rural youth: a promising but imperfect fit. J Adolesc Health. 2006;38(1):55. 
21. Stanton B, Cole M, Galbraith J, et al. Randomized trial of a parent intervention: parents can make a difference in long-term adolescent risk behaviors, perceptions, and knowledge. Arch Pediatr Adolesc Med. 2004;158(10):947-955.

22. Moberg DP, Piper DL. The Healthy for Life Project: sexual risk behavior outcomes. AIDS Educ Prev. 1998;10(2):128-148.

23. Jemmott JM, Jemmott LS, Braverman PK, Fong GT. HIV/STD risk reduction interventions for African American and Latino adolescent girls at an adolescent medicine clinic. Arch Pediatr Adolesc Med 2005;159(5):440-449.

24. Jemmott JB, Jemmott LS, Fong GT. Efficacy of a theory-based abstinence-only intervention over 24 months: a randomized controlled trial with young adolescents. Arch Pediatr Adolesc Med. 2010;164(2): $152-159$.

25. Thomas BH, Mitchell A, Devlin MC, Goldsmith CH, Singer J, Watters D. Small group sex education at school: the McMaster Teen Program. In: Miller BC, Card JJ, Paikoff RL, Perterson JL, editors. Preventing Adolescent Pregnancy. Newbury Park (CA): Sage; 1992.

26. Tolou-Shams M, Houck C, Conrad SM, Tarantino N, Stein LA, Brown LK. HIV prevention for juvenile drug court offenders: a randomized controlled trial focusing on affect management. J Correct Health Care. 2011;17(3):226-232.

27. Stephenson JM, Strange V, Forrest S, et al. Pupil-led sex education in England (RIPPLE study): cluster-randomised intervention trial. Lancet. 2004;364(9431):338-346.

28. Stephenson JM, Strange V, Allen E, et al. The long-term effects of a peer-led sex education programme (RIPPLE): a cluster randomised trial in schools in England. PLoS Med. 2008;5(11):e224.

29. Kirby D, Korpi M, Barth RP, Cagampang HH. The impact of the Postponing Sexual Involvement curriculum among youths in California. Fam Plann Perspect. 1997;29(3):100-108.

30. Sznitman S, Vanable PA, Carey MP, et al. Using culturally sensitive media messages to reduce HIV-associated sexual behavior in high-risk African American adolescents: results from a randomized trial. JAdolesc Health. 2011;49(3):244-251.

31. Kirby D, Korpi M, Adivi C, Weissman J. An impact evaluation of Project SNAPP: an AIDS and pregnancy prevention middle school program. AIDS Educ Prev. 1997;9(1 Suppl):44-61.

32. Basen-Engquist K, Coyle K, Parcel G, Kirby DB, Banspach S, Carvajal S. Schoolwide effects of a multicomponent HIV, STD, and pregnancy prevention program for high school students. Health Educ Behav. 2001;28(2):166-185.

33. Gillmore MR, Morrison DM, Richey CA, Balassone ML, Gutierrez L, Farris M. Effects of a skill-based intervention to encourage condom use among high risk heterosexually active adolescents. AIDS Educ Prev. 1997;9(1 Suppl):22-43.

34. Brown KE, Hurst KM, Arden MA. Improving adolescent contraceptive use: evaluation of a theory-driven classroom-based intervention. Psychol Health Med. 2011;16(2):141-155.
35. Schmiege SJ, Broaddus MR, Levin M, Bryan AD. Randomized trial of group interventions to reduce HIV/STD risk and change theoretical mediators among detained adolescents. J Consult Clin Psychol. 2009;77(1):38-50.

36. Levy SR, Perhats C, Weeks K, Handler AS, Zhu C, Flay BR. Impact of a school-based AIDS prevention program on risk and protective behavior for newly sexually active students. J Sch Health. 1995;65(4): 145-151.

37. Weeks K, Levy SR, Gordon AK, Handler A, Perhats C, Flay B. Does parental involvement make a difference? The impact of parent interactive activities on students in a school-based AIDS prevention program. AIDS Educ Prev. 1997;9(1 Suppl):90-106.

38. Blake SM, Simkin L, Ledsky R, Perkins C, Clabrese JM. Effects of a parentchild communications intervention on young adolescents' risk for early onset of sexual intercourse. Fam Plann Perspect. 2001;33(2): 52-61.

39. Haggerty KP, Skinner ML, MacKenzie EP, Catalano RF. A randomized trial of Parents Who Care: effects on key outcomes at 24-month followup. Prev Sci. 2007;8(4):249-260.

40. Dynarski M, Gleason P, Rangarajan A, Wood R. Impacts of Dropout Prevention Programs: Final Report. Princeton (NJ): Mathematica Policy Research; 1998.

41. Schochet P, Burghardt J, Glazerman S. National Job Corps Study: The Short-Term Impacts of Job Corps on Participants and Related Outcomes. Washington: US Department of Labor, Employment and Training Administration; 2000.

42. Schochet P, Brughardt J, Glazerman S. National Job Corps Study: The Impacts of Job Corps on Participants' Employment and Related Outcomes. Princeton (NJ): Mathematica Policy Research; 2001.

43. Cave G, Bos H, Doolittle F, Toussaint C. JOBSTART: Final Report on a Program for School Dropouts. New York: Manpower Demonstration Research; 1993.

44. Cave G, Doolittle F. JOBSTART: Interim Impacts of a Program for School Dropouts. New York: Manpower Demonstration Research; 1991.

45. Maxfield M, Schirm A, Rodriguez-Planas N. The Quantum Opportunity Program Demonstration: Implementation and Short-Term Impacts. Washington: Mathematica Policy Research; 2003.

46. Schirm A, Rodriguez-Planas N. The Quantum Opportunity Program Demonstration: Initial Post-Intervention Impacts. Washington: Mathematica Policy Research; 2004.

47. Schirm A, Stuart E, McKie A. The Quantum Opportunity Program Demonstration: Final Impacts. Washington: Mathematica Policy Research; 2006.

48. Walker G, Vilella-Velez F. Long-term impacts. In: Anatomy of a Demonstration: The Summer Training and Education Program (STEP) from Pilot Through Replication and Postprogram Impacts. Philadelphia: Public/Private Ventures; 1992.

49. Walker G, Vilella-Velez F. Testing the model. In: Anatomy of a Demonstration: The Summer Training and Education Program (STEP) from Pilot Through Replication and Postprogram Impacts. Philadelphia: Public/Private Ventures; 1992.

Adolescent Health, Medicine and Therapeutics

\section{Publish your work in this journal}

Adolescent Health, Medicine and Therapeutics is an international, peer-reviewed, open access journal focusing on health, pathology, and treatment issues specific to the adolescent age group. All aspects of health maintenance, preventative measures and disease treatmen interventions are addressed within the journal and practitioners from

all disciplines are invited to submit their work as well as healthcare researchers and patient support groups.. The manuscript management system is completely online and includes a very quick and fair peerreview system. Visit http://www.dovepress.com/testimonials.php to read real quotes from published authors. 